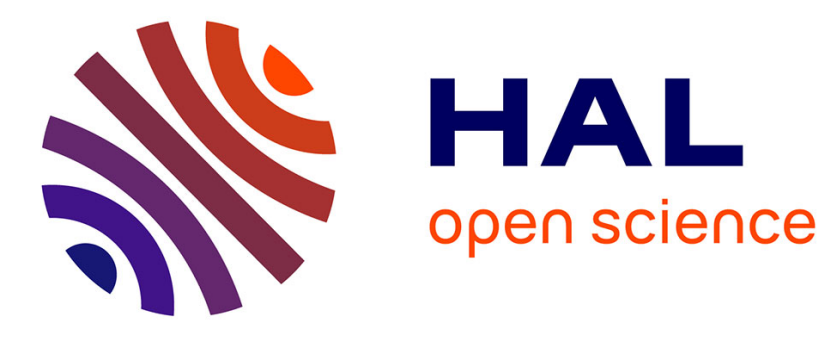

\title{
Multi-model evaluation of phenology prediction for wheat in Australia
}

\author{
Daniel Wallach, Taru Palosuo, Peter Thorburn, Zvi Hochman, Fety \\ Andrianasolo, Senthold Asseng, Bruno Basso, Samuel Buis, Neil Crout, \\ Benjamin Dumont, et al.
}

\section{To cite this version:}

Daniel Wallach, Taru Palosuo, Peter Thorburn, Zvi Hochman, Fety Andrianasolo, et al.. Multi-model evaluation of phenology prediction for wheat in Australia. Agricultural and Forest Meteorology, 2021, 298-299, 10.1016/j.agrformet.2020.108289 . hal-03119039

\section{HAL Id: hal-03119039 \\ https://hal.inrae.fr/hal-03119039}

Submitted on 26 Nov 2021

HAL is a multi-disciplinary open access archive for the deposit and dissemination of scientific research documents, whether they are published or not. The documents may come from teaching and research institutions in France or abroad, or from public or private research centers.
L'archive ouverte pluridisciplinaire HAL, est destinée au dépôt et à la diffusion de documents scientifiques de niveau recherche, publiés ou non, émanant des établissements d'enseignement et de recherche français ou étrangers, des laboratoires publics ou privés.

\section{(c)(1)}

Distributed under a Creative Commons Attribution| 4.0 International License 


\section{Multi-model evaluation of phenology prediction for wheat in Australia}

Wallach ${ }^{1}$, Daniel; Palosuo², Taru; Thorburn ${ }^{3}$, Peter; Hochman ${ }^{3}$, Zvi; Andrianasolo ${ }^{4}$, Fety; Asseng ${ }^{5}$, Senthold; Basso ${ }^{6}$, Bruno; Buis ${ }^{7}$, Samuel; Crout ${ }^{8}$, Neil; Dumont ${ }^{9}$, Benjamin; Ferrise ${ }^{10}$, Roberto; Gaiser ${ }^{11}$, Thomas; $^{2}$ Gayler $^{12}$, Sebastian; Hiremath ${ }^{13}$, Santosh; Hoek ${ }^{14}$, Steven; Horan ${ }^{3}$, Heidi; Hoogenboom ${ }^{5,15}$, Gerrit; Huang ${ }^{16}$, Mingxia; Jabloun ${ }^{8}$, Mohamed; Jansson ${ }^{17}$, Per-Erik; Jing ${ }^{18}$, Qi; Justes ${ }^{19}$, Eric; Kersebaum ${ }^{20,21}$, Kurt Christian; Launay $^{22}$, Marie; Lewan ${ }^{23}$, Elisabet; Luo ${ }^{24}$, Qunying; Maestrini1 ${ }^{14}$, Bernardo; Moriondo ${ }^{25}$, Marco; Padovan ${ }^{10}$, Gloria; Olesen ${ }^{26}$, Jørgen Eivind; Poyda ${ }^{27}$, Arne; Priesack ${ }^{28}$, Eckart; Pullens ${ }^{26}$, Johannes Wilhelmus Maria; Qian ${ }^{18}$, Budong; Schütze ${ }^{29}$, Niels; Shelia ${ }^{5,15}$, Vakhtang; Souissi ${ }^{30,31}$, Amir; Specka ${ }^{20}$, Xenia; Srivastava ${ }^{11}$, Amit Kumar; Stella ${ }^{20}$, Tommaso; Streck ${ }^{12}$, Thilo; Trombi ${ }^{10}$, Giacomo; Wallor ${ }^{20}$, Evelyn; Wang ${ }^{16}$, Jing; Weber ${ }^{12}$, Tobias, K.D.; Weihermüller ${ }^{32}$, Lutz; de Wit ${ }^{14}$, Allard; Wöhling ${ }^{29,33}$, Thomas; Xiao ${ }^{5,34}$, Liujun; Zhao ${ }^{5}$, Chuang; Zhu ${ }^{34}$, Yan; Seidel, Sabine J. ${ }^{11}$

${ }^{1}$ INRAE, UMR AGIR, Castanet Tolosan, France. ORCID 0000-0003-3500-8179

${ }^{2}$ Natural Resources Institute Finland (Luke), Helsinki, Finland

${ }^{3}$ CSIRO Agriculture and Food, Brisbane, Queensland, Australia

${ }^{4}$ ARVALIS - Institut du végétal Paris, France

${ }^{5}$ Agricultural and Biological Engineering Department, University of Florida, Gainesville, Florida

${ }^{6}$ Department of Earth and Environmental Sciences, Michigan State University, East Lansing, Michigan

${ }^{7}$ INRAE, UMR 1114 EMMAH, Avignon, France

${ }^{8}$ School of Biosciences, University of Nottingham, Loughborough, UK

${ }^{9}$ Plant Sciences \& TERRA Teaching and Research Centre, Gembloux Agro-Bio Tech, University of Liege, Gembloux, Belgium

${ }^{10}$ Department of Agriculture, Food, Environment and Forestry (DAGRI), University of Florence, Italy

${ }^{11}$ Institute of Crop Science and Resource Conservation, University of Bonn, Germany

${ }^{12}$ Institute of Soil Science and Land Evaluation, Biogeophysics, University of Hohenheim, Stuttgart, Germany

${ }^{13}$ Aalto University School of Science, Espoo, Finland

${ }^{14}$ Wageningen University \& Research, Wageningen, The Netherlands

${ }^{15}$ Institute for Sustainable Food Systems, University of Florida, Gainesville, Florida

${ }^{16}$ College of Resources and Environmental Sciences, China Agricultural University, Beijing, China

${ }^{17}$ Royal Institute of Technology (KTH), Stockholm, Sweden

${ }^{18}$ Ottawa Research and Development Centre, Agriculture and Agri-Food Canada, Ottawa, Canada

${ }^{19}$ CIRAD, UMR SYSTEM, Montpellier, France

${ }^{20}$ Leibniz Centre for Agricultural Landscape Research, Müncheberg, Germany

${ }^{21}$ Global Change Research Institute CAS, Brno, Czech Republic

${ }^{22}$ INRAE, US 1116 AgroClim, Avignon, France

${ }^{23}$ Department of Soil and Environment, Swedish University of Agricultural Sciences (SLU), Uppsala, Sweden ${ }^{24}$ Hillridge Technology Pty Ltd, Sydney, Australia 
${ }^{25}$ CNR-IBE, Firenze, Italy

$40 \quad{ }^{26}$ Department of Agroecology, Aarhus University, Tjele, Denmark

$41{ }^{27}$ Grass and Forage Science / Organic Agriculture, Institute of Crop Science and Plant Breeding, Kiel University,

42 Kiel, Germany

$43{ }^{28}$ Institute of Biochemical Plant Pathology, Helmholtz Zentrum München-German Research Center for

44 Environmental Health, Neuherberg, Germany

$45{ }^{29}$ Institute of Hydrology and Meteorology, Chair of Hydrology, Technische Universität Dresden, Dresden,

46 Germany

$47{ }^{30}$ National Institute of Agronomic Research of Tunisia (INRAT), Agronomy Laboratory, University of Carthage,

48 Tunis, Tunisia

$49 \quad{ }^{31}$ National Agronomy Institute of Tunisia (INAT), University of Carthage, Tunis, Tunisia

$50 \quad{ }^{32}$ Institute of Bio- and Geosciences - IBG-3, Agrosphere, Forschungszentrum Jülich GmbH, Jülich, Germany

$51 \quad{ }^{33}$ Lincoln Agritech Ltd., Hamilton, New Zealand

$52{ }^{34}$ National Engineering and Technology Center for Information Agriculture, Jiangsu Key Laboratory for

53 Information Agriculture, Jiangsu Collaborative Innovation Center for Modern Crop Production, Nanjing

54 Agricultural University, Nanjing, Jiangsu, China 


\section{Abstract}

Predicting wheat phenology is important for cultivar selection, for effective crop management and provides a baseline for evaluating the effects of global change. Evaluating how well crop phenology can be predicted is therefore of major interest. Twenty-eight wheat modeling groups participated in this evaluation. Our target population was wheat fields in the major wheat growing regions of Australia under current climatic conditions and with current local management practices. The environments used for calibration and for evaluation were both sampled from this same target population. The calibration and evaluation environments had neither sites nor years in common, so this is a rigorous evaluation of the ability of modeling groups to predict phenology for new sites and weather conditions. Mean absolute error (MAE) for the evaluation environments, averaged over predictions of three phenological stages and over modeling groups, was 9 days, with a range from 6 to 20 days. Predictions using the multimodeling group mean and median had prediction errors nearly as small as the best modeling group. About two thirds of the modeling groups performed better than a simple but relevant benchmark, which predicts phenology by assuming a constant temperature sum for each development stage. The added complexity of crop models beyond just the effect of temperature was thus justified in most cases. There was substantial variability between modeling groups using the same model structure, which implies that model improvement could be achieved not only by improving model structure, but also by improving parameter values, and in particular by improving calibration techniques. uncertainty 


\section{Introduction}

Crop phenology describes the cycle of biological events during plant growth. These events include, for example, seedling emergence, leaf appearance, flowering, and maturity. Timing of growing seasons and their critical phases as well as estimates of them are increasingly important in changing climate (Olesen et al., 2012, Dalhaus et al., 2018). Matching the phenology of crop varieties to the climate in which they grow is critical for viable crop production strategies (Rezaei et al., 2018, Hunt et al., 2019). Furthermore, accurate simulation of phenology is essential for models which simulate plant growth and yield (Archontoulis et al., 2014; Boote et al., 2010, 2008).

In this study we focus on wheat phenology in Australia. Australia was the world's ninth largest producer of wheat in 2018 and the sixth largest exporter (Workman, 2020). Crop model predictions of phenology have been used in various studies related to wheat production in Australia. In a study by Luo et al. (2018), the APSIM model was used to simulate changes in phenology, water use efficiency, and yield to be expected from global climate change. The APSIM model was used to evaluate changes in wheat phenology in Australia as a result of warming temperatures in recent decades (Sadras and Monzon, 2006). That model was also used to determine the flowering date at each location associated with highest average yield (Flohr et al., 2017).

Given the interest in using crop models to predict phenology, it is important to evaluate those predictions. How well can wheat phenology be predicted? In trying to answer this question, one must first define exactly what aspect of the models is being evaluated, and then must choose an appropriate methodology for carrying out the evaluation. 
differ as to whether or not the data provided for calibration are representative of the target

103 population, i.e. of the range of environments of interest. In one type of study, the objective is

104 to evaluate how well models can extrapolate to conditions not represented in the calibration

105 data. For example, in a multi-model ensemble study on the effect of high temperatures on wheat

106 growth (Asseng et al., 2015), detailed crop measurements were provided for one planting date

107 and the models were evaluated using other planting dates, some with additional artificial heating

108 during growth. The evaluation data thus represented a much larger range of temperatures than represented in the calibration data. This was a test of how well the models can extrapolate to more extreme temperatures than those available for calibration. Other studies have evaluated how well crop models can extrapolate to environments with enhanced $\mathrm{CO}_{2}$, given calibration data for current ambient $\mathrm{CO}_{2}$ levels (Biernath et al., 2011).

114 target population. This evaluates how well crop models can generalize from the calibration 115 environments to other similar environments. An example is the study by Ceglar et al. (2019), 116 which used data on wheat phenology under current conditions in Europe for calibration and 117 then predicted phenology for other environments from the same target population. This type of 118 evaluation is adapted, for example, to the case where one has data from a network of variety 119 trials and wants to predict for other sites and years from the same target population, as in Bao 120 et al.. (2017) for yield. It is this aspect of crop phenology models, namely their ability to predict 121 when provided with a sample of data from the target population, that is evaluated in the present 122 study.

A second aspect of evaluation that must be specified is the modeling group or groups

124 that are being evaluated, where modeling group refers to the combination of crop model and 125 the people responsible for running the simulations. We reserve the term "model" specifically 126 for model structure, i.e. the model equations, while modeling group determines both the model 
structure and the parameter values, which are chosen or estimated by the group running the model. It is clear that predictions depend not only on the model structure but also on the parameter values, so evaluation really refers to the modeling group. Model evaluation studies may refer to a particular modeling group or to an ensemble of modeling groups. Here, we evaluate an ensemble of 28 different modeling groups. The purpose is not to give information about each specific modeling group, but rather to evaluate how well currently active modeling groups can predict phenology for our target population (e.g. what is the error of the best predicting group), how well can one expect a modeling group chosen at random to predict (e.g. what is the mean or median prediction error), and what is the variability between modeling groups (e.g. what is the spread between the best and worst predictors).

It is important to define precisely the evaluation problem (extrapolation or interpolation, single- or multi-group evaluation), but it is also important that the methodology of evaluation be such as to give reliable results. We focus here on the relation of the predictor (model plus parameter values) and evaluation data. It is well-known from statistics that if a predictor is not independent of the evaluation data, then the error for the evaluation data will in general be less than for new environments (Efron, 1986). That is, non-independence in general leads to underestimating prediction errors. The predictor could depend on the evaluation data if, for example, the evaluation data were also used to calibrate the model, or were used to modify the model equations, or were used to tune site characteristics. If the same sites are present in the calibration and evaluation data, then the model has to some extent been tuned to those sites, and so the predictor is not independent of the evaluation data even if the evaluation data have not been used directly to fit the model. Having the same sites in the calibration and evaluation data is often the case for evaluation studies (Andarzian et al., 2015; Asseng et al., 2008; Chauhan et al., 2019; Hussain et al., 2018; Yuan et al., 2017). 
152 in Australia based on results from multiple modeling groups, where the calibration data are

153 sampled from the target population (i.e. evaluation of interpolation predictions). The purpose

154 of this study is to present such an evaluation, using a rigorous approach where the parameterized

155 model is independent of the evaluation data.

\section{2. Materials and Methods}

\subsection{Experimental data}

The data are a subset from a multi-cultivar, multi-location, and multi-sowing date trial

159 for wheat in Australia, described in Lawes et al. (2016). The environments reflect the diversity

160 in the wheat-growing regions of Australia (Fig. 1). Only the data for cultivar Janz, classified as

161 a fast-moderate maturing cultivar, were used here. The data are from 10 sites, located

162 throughout the grain growing region each with one to three sowing years and three planting

163 dates in each year (overall 66 environments, i.e. site-sowing date combinations, Table 1). The

164 sowing dates at each site correspond to early, conventional, and late sowing. Plant density was

165 100-120 plants $/ \mathrm{m}^{2}$, and sowing depth was 20-35 mm. Nutrients were managed to be non-

166 limiting. There were 1-3 repetitions for each environment (average of 2.1 repetitions). 


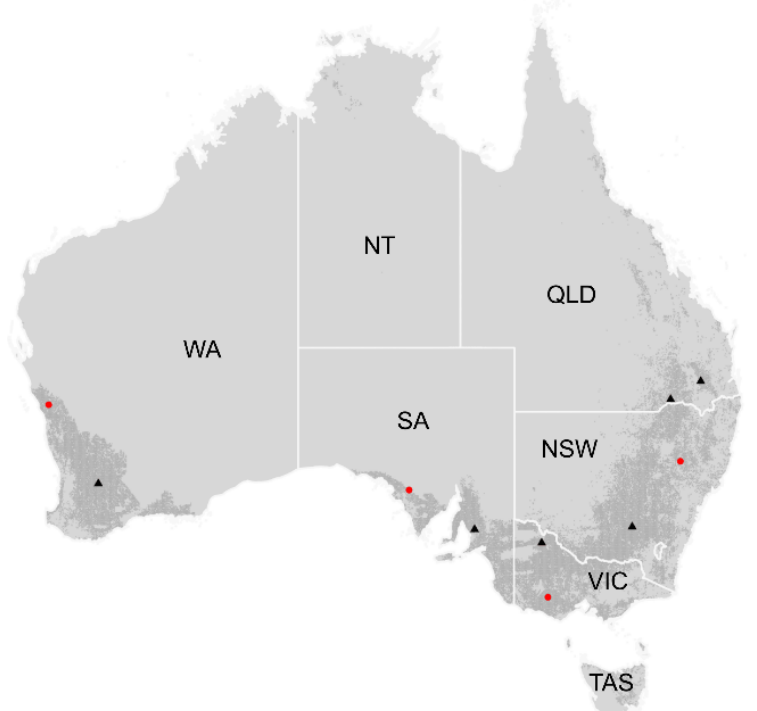

173 the early sowing and ending after crop maturity, and the Zadoks growth stage (Zadoks et al., 174 1974), on a scale from 1-100, was determined. Overall, there were 709 combinations of 175 environment and measurement date, with an average of 10.7 stage notations per environment.

176 The stages to be predicted here are stage Z30 (Zadoks stage 30, pseudostem, i.e. youngest leaf 177 sheath erection), stage Z65 (Zadoks stage 65, anthesis half-way, i.e. anthers occurring half way to tip and base of ear), and stage Z90 (Zadoks stage 90, grain hard, difficult to divide). These stages are often used for management decisions or to characterize phenology. between each pair of stages, to give the date for every integer Zadoks stage from the first to the

182 last observed stage. At 10 of the 709 measurement dates, observed Zadoks stage decreased 183 slightly (by an average of 3 on the Zadoks scale) compared to the previous date, due to sampling 184 variability. In that case both observed Zadoks stages were replaced by the average for the two 
dates, before interpolation. The interpolated values were provided in order to avoid different modeling groups using different methods for interpolating the data, which would have added additional uncertainty unrelated to the model performance. 0.93 days. The standard deviation of interpolated days after sowing to Z30, Z65, and Z90 was calculated using a bootstrap. For a day with $r$ replicates, a sample of size $r$ was obtained by drawing values at random with replacement, independently for each measurement date. Then the Zadoks values were interpolated as for the original data. This was done 1000 times, giving standard deviations of 1.8 days for observed days to Z30, 0.9 days for observed days to Z65, and 0.5 days for observed days to Z90, respectively. two years, and three planting dates, so overall 24 environments. The evaluation data were from

198 six sites, one year, and three planting dates for a total of 18 environments (Table 1). Dates of

\begin{tabular}{|l|r|r|r|}
\hline sitel year & 2010 & 2011 & 2012 \\
\hline Bungunya & & & $\mathbf{2 0 1 2 - 0 5 - 1 0}$ \\
(Queensland) & & & $\mathbf{2 0 1 2 - 0 5 - 2 2}$ \\
\hline
\end{tabular}




\begin{tabular}{|c|c|c|c|}
\hline & & & $2012-06-23$ \\
\hline $\begin{array}{l}\text { Corrigin } \\
\text { (West Australia) }\end{array}$ & & & $\begin{array}{l}2012-05-02 \\
2012-05-21 \\
2012-06-21\end{array}$ \\
\hline $\begin{array}{l}\text { Eradu } \\
\text { (West Australia) }\end{array}$ & $\begin{array}{l}\underline{2010-05-14} \\
\underline{2010-05-27} \\
\underline{2010-06-22}\end{array}$ & $\begin{array}{l}\underline{2011-04-29} \\
\underline{2011-05-24} \\
\underline{2011-06-23} \\
\end{array}$ & \\
\hline $\begin{array}{l}\text { LakeBolac } \\
\text { (Victoria) }\end{array}$ & $\begin{array}{l}\underline{2010-05-03} \\
\underline{2010-05-19} \\
\underline{2010-07-08} \\
\end{array}$ & $\begin{array}{l}\underline{2011-05-09} \\
\underline{2011-06-03} \\
\underline{2011-06-16} \\
\end{array}$ & \\
\hline $\begin{array}{l}\text { Minnipa } \\
\text { (South Australia) }\end{array}$ & $\begin{array}{l}\underline{2010-04-30} \\
\underline{2010-05-31} \\
2010-06-24 \\
\end{array}$ & $\begin{array}{l}\underline{2011-05-13} \\
\underline{2011-05-27} \\
2011-06-24 \\
\end{array}$ & \\
\hline $\begin{array}{l}\text { Nangwee } \\
\text { (Queensland) }\end{array}$ & & & $\begin{array}{l}2012-05-17 \\
2012-05-31 \\
2012-06-23\end{array}$ \\
\hline $\begin{array}{l}\text { Spring Ridge } \\
\text { (New South Wales) }\end{array}$ & $\begin{array}{l}\underline{2010-05-10} \\
\underline{2010-06-11} \\
\underline{2010-07-01}\end{array}$ & $\begin{array}{l}\underline{2011-05-09} \\
\underline{2011-06-06} \\
\underline{2011-06-23}\end{array}$ & \\
\hline $\begin{array}{l}\text { Temora } \\
\text { (New South Wales) }\end{array}$ & & & $\begin{array}{l}2012-05-05 \\
2012-05-23 \\
2012-06-25\end{array}$ \\
\hline $\begin{array}{l}\text { Turretfield } \\
\text { (South Australia) }\end{array}$ & & & $\begin{array}{l}2012-05-30 \\
2012-06-15 \\
2012-07-05\end{array}$ \\
\hline
\end{tabular}


bioRxiv preprint doi: https://doi.org/10.1101/2020.06.06.133504; this version posted December 15,2020 . The copyright holder for this preprint (which was not certified by peer review) is the author/funder. All rights reserved. No reuse allowed without permission.

205

\begin{tabular}{|l|l|l|l|}
\hline Walpeup & & & 2012-04-27 \\
(Victoria) & & 2012-06-04 \\
& & $\mathbf{2 0 1 2 - 0 7 - 1 8}$ \\
\hline
\end{tabular}

206 
To characterize the environments, we calculated for each environment the average 209 temperature from sowing to Z30, Z65, and Z90, the average photoperiod from Z30 to Z65 using

210 the daylength function in the R package insol (Corripio, 2019.; R Core Team, 2017) and days

211 to full vernalization using the model in van Bussel et al. (2015) with a required duration of

212 exposure to vernalizing temperatures ( $V_{\text {sat }}$ ) of 25 days, estimated from the figure in their paper.

213 Figure 2 shows the range of average temperature, day length, and days to vernalization for the

214 calibration and evaluation environments as well as the range of observed calendar days to Z30,

215 Z65, and Z90. The range of values for the evaluation data is always within the range of the

216 calibration data, with the single exception of photoperiod. While the median and maximum day

217 lengths were very similar for the two sets of environments, the shortest day length was 11.5

218 hours among calibration environments, while among the evaluation environments the shortest

219 day length was 10.1 hours. 

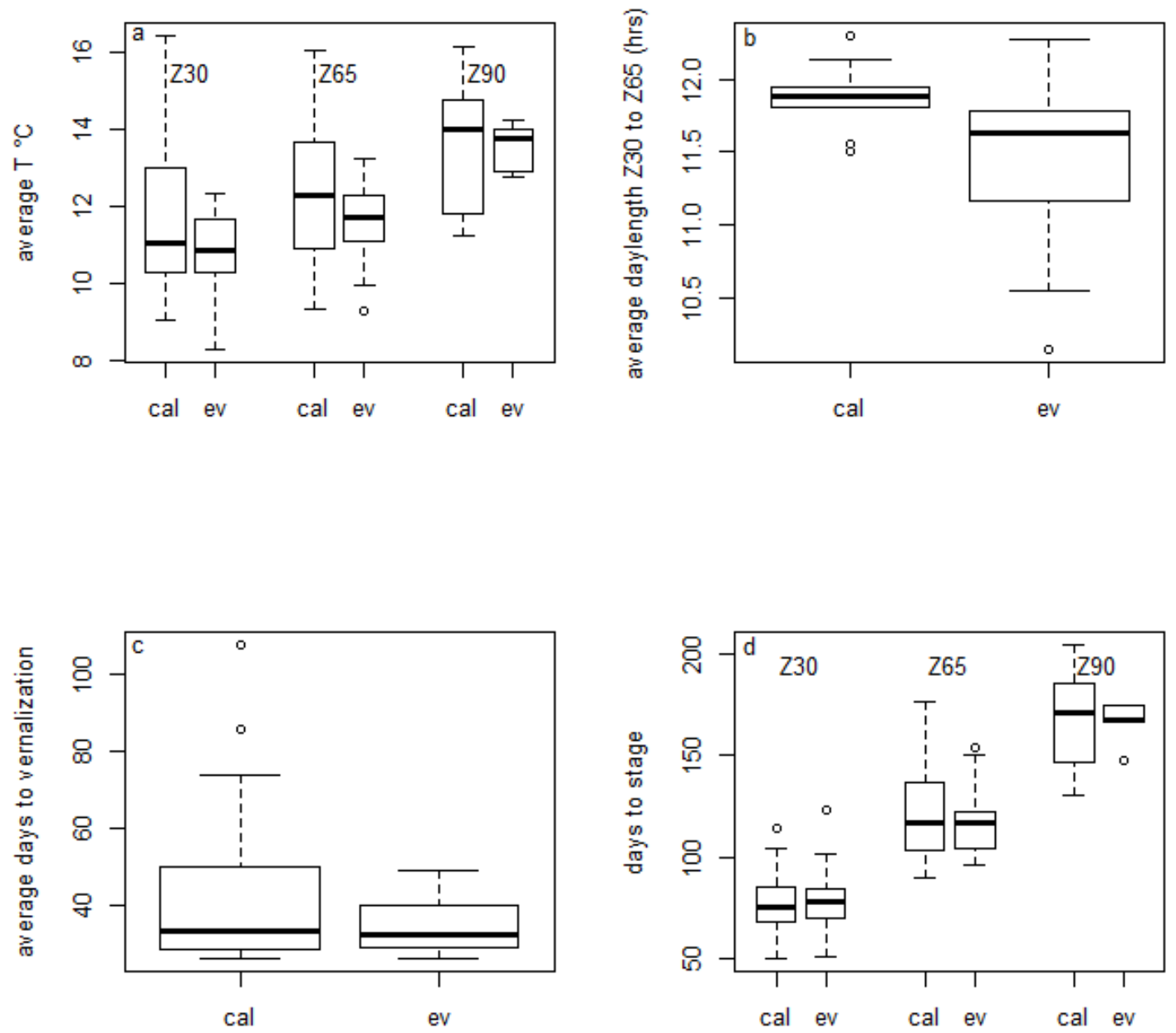

Boxplots of a) average temperatures from sowing to Zadoks stages Z30, Z65, and average days from sowing to complete vernalization d) average days from sowing to Zadoks stages Z30, Z65, and Z90. Results are shown separately for the calibration (ca) and evaluation (ev) environments. Boxes indicate the lower and upper quartiles. The solid line within the box is the median. Whiskers indicate the most extreme data point which is no more than 1.5 times the interquartile range from the box, and the outlier dots are those observations that are beyond that range. 


\subsection{Modeling groups}

Twenty-eight different modeling groups participated in this study, where modeling

233 group refers to the group of people conducting the modeling exercise. Each modeling group is associated with some specific model structure (some specific named model) and also with some specific parameter values. The model structures involved are presented in Supplementary Table

S1. Models were considered to have the same structure even if the version number was different, because version differences are expected to be negligible for phenology. Three of the model structures were used by more than one group. Since different groups using the same structure obtained different results, identifying the contributions by the name of the model would be misleading. Furthermore, the performance of specific groups was not of major interest here. Therefore the modeling groups were anonymized, and only identified by a number. There is no model M5 because that group dropped out in the course of the study. The model structures used by more than one group are noted S1 (three groups), S2 (three groups) and S3 (two groups). the references for each model (Supplementary Table S1). Here we give only a brief overview.

246 The principal factors that affect winter wheat developmental rate are temperature, day length and degree of vernalization (Johnen et al., 2012). Most, but not all, model structures take into account all three factors. The simplest approach to modeling the effect of temperature is to assume that development rate increases linearly with daily average temperature above some base temperature (a parameter). In other models the rate may be constant above some optimal 251 temperature (a parameter), development rate may decline above the optimum temperature at 252 some rate (a parameter), or development rate may be some more complex function of 253 temperature (Kumudini et al., 2014; Wang et al., 2017). The parameters of the temperature 254 response curve may differ depending on development stage. The effect of photoperiod on 255 development rate is often modeled as a multiplier that is a piecewise linear function of 
256 photoperiod. The function increases with some slope (a parameter) up to a threshold 257 photoperiod (a parameter), and then is 1 for photoperiods longer than the threshold. 258 Vernalization, which must be accomplished before the plant can flower, requires a period of 259 cold temperatures. Vernalization parameters can include the upper limit for temperature to 260 count as vernalizing, and the required number of vernalizing days. Some models also relate 261 development to the rate of leaf appearance (called the phyllochron, a parameter) or rate of 262 tillering. Finally, several models also take into account the effect of cold or drought stress on 263 development rate. If drought stress is taken into account, then development rate is related to all 264 the processes that determine soil moisture and plant water uptake.

The multi-model ensemble here was an "ensemble of opportunity" meaning that any 266 modeling group that asked to join was accepted. The activity was announced on the list server 267 of the Agricultural Modeling Inter-comparison and Improvement Project (AgMIP) and on the 268 list servers of several models. In addition to the original models, we defined two ensemble 269 models. The model e-mean has predictions equal to the mean of the simulated values. The 270 model e-median has predictions equal to the median of the simulated values.

\subsection{Simulation experiment}

Each participating modeling group was provided with weather, soil, and management

273 data for all environments, as well as all available observed and interpolated values for days to 274 each Zadoks stage for the calibration data. Participants were requested to return simulated 275 values for number of days from sowing to emergence (even though days to emergence was never observed) and values for number of days from sowing to stages Z30, Z65, and Z90 for

277 all environments, including both the calibration environments and the evaluation environments. 


\subsection{Evaluation} $m$, MAE is

$$
M A E_{m}=(1 / n) \sum_{i=1}^{n}\left|y_{i}-\hat{y}_{i, m}\right|
$$

where $y_{i}$ is the observed value for environment $i$ and $\hat{y}_{i, m}$ is the value simulated by modeling

MSE, MAE does not give extra weight to large errors (Willmott and Matsuura, 2005). To test

studies.

$$
\begin{aligned}
& \operatorname{MSE}_{m}=(1 / n) \sum_{i=1}^{n}\left(y_{i}-\hat{y}_{i, m}\right)^{2} \\
& R M S E_{m}=\sqrt{M S E_{m}} \\
& N R M S E_{m}=R M S E_{m} / \bar{y}
\end{aligned}
$$

292 where $\bar{y}$ is the average of the observed values.

We considered two skill measures. A skill measure compares prediction error of the

294 modeling group to be evaluated with the error of a simple model used for comparison. We

295 define two simple models, and therefore two skill measures. Both use MSE, rather than MAE, 296 as the measure of model error, in keeping with usual practice. The first simple model, noted 297 "naive", predicts that days to each stage will be equal to the average number of days to that 
stage in the calibration data. The predictions of the naïve model here are 77.1, 123.1, and 166.5 days from sowing to stages Z30, Z65, and Z90, respectively. The first skill measure, modeling efficiency (EF), is defined as

$$
E F_{m}=1-M S E_{m} / M S E_{\text {naive }}
$$

The naive model ignores all variability and predicts that days to any stage will be the same regardless of the environment. A model with $\mathrm{EF} \leq 0$ is a model that does no better than the naive model, and so would be considered a very poor predictor. A perfect model, with no error, has modeling efficiency of 1 . Often modeling efficiency is based on the fit of a calibrated model to the data used for calibration (McCuen et al., 2006). Here, in contrast, the naïve model is based on calibration data and used to predict for independent data.

The naïve model is a very low baseline for evaluating a crop model. We therefore introduce a more realistic, but still simple model which takes into account the effect of temperature on phenology. This "only T" model predicts that degree days $\left({ }^{\circ} \mathrm{D}\right)$ from sowing to each stage will be equal to the number of degree days from sowing to that stage in the calibration data, where degree days on any calendar day is equal to average temperature that day. The predictions of the onlyT model are that Z30 will occur $893.7^{\circ} \mathrm{D}$ after sowing, Z65 will occur $1476.0^{\circ} \mathrm{D}$ after sowing, and Z90 will occur $2245.7^{\circ} \mathrm{D}$ after sowing. The second skill measure, noted skillT, is then

$$
\operatorname{skillT}_{m}=1-M S E_{m} / M S E_{\text {onlyT }}
$$

where $M S E_{\text {onlyT }}$ is MSE for the onlyT model. As for any skill measure, a perfect model has skillT $=1$ and a model that does no better than the onlyT model has skillT $\leq 0$ 


\subsection{Sources of variability}

A major interest of ensemble studies is that they provide information on the variability in simulation results between different modeling groups. This variability can arise from differences in model structure between different modeling groups or differences in parameter values for groups that use the same model structure. In this study, three of the model structures are used by more than one modeling group. This makes it possible to estimate separately the variance in simulated values due to structure and the variance due to modeling group nested within structure (i.e. due to differences in parameter values). We treat the simulated values as a sample from the distribution of plausible model structures and plausible parameter values. According to the law of total variance (Casella and Berger, 1990), the total variance of simulated values can be decomposed into two parts as

$$
\operatorname{var}(\hat{y})=\operatorname{var}[E(\hat{y} \mid S)]+E[\operatorname{var}(\hat{y} \mid S)]
$$

331 where $\hat{y}$ are the simulated values, $S$ is model structure, $\mathrm{E}$ is the expectation, var is the variance, 332 and the notation $\mid \mathrm{S}$ means that the expectation (in the first term on the right hand side) or the 333 variance (in the second term on the right hand side) is taken separately for each value of model 334 structure. We estimated the first term by first calculating the average simulated value for each 335 structure (if a structure is represented by a single modeling group, this is just the value simulated 336 by that group), and then calculating the variance of those average values. This is the between337 structure variability. To estimate the second term, we first calculated the variance between 338 simulated values for each of the three structures with multiple groups. Then we calculated the 339 average of those variances. This is the within-structure variability (i.e. variability due to 340 parameters). 


\section{Results}

\subsection{Prediction error and skill}

MAE values for the evaluation data are shown in Figure 3 and summarized in Table 2.

344 Results for individual modeling groups are given in Supplementary Table S2. Median MAE 345 values (and ranges) were 12 days (8-25 days) for days to Z30, 10 days (5-24 days) for days to 346 Z65, and 7 days (1-22 days) for days to Z90. The median (and range) of MAE averaged over 347 the three stages was 9 days (6-20 days). The ensemble predictors e-mean and e-median both 348 had averaged MAE values of 7 days. They were both only marginally worse than the best two 349 individual modeling groups, and e-median was marginally better than e-mean. For comparison 350 with other studies, we also report other criteria of error in Table 2.

median, minimum, and maximum error over modeling groups are shown.

\begin{tabular}{|l|l|l|l|l|}
\hline & & median & minimum & maximum \\
\hline Evaluation data & MAE (days) & 9 & 6 & 20 \\
\cline { 2 - 6 } & RMSE (days) & 12 & 9 & 25 \\
\cline { 2 - 6 } & NRMSE & 0.094 & 0.056 & 0.227 \\
\cline { 2 - 6 } & EF & 0.51 & -1.51 & 0.70 \\
\cline { 2 - 6 } & skillT & 0.2 & -3.34 & 0.49 \\
\hline Calibration data & MAE (days) & 8 & 6 & 24 \\
\cline { 2 - 6 } & RMSE (days) & 11 & 6 & 19 \\
\hline
\end{tabular}




\begin{tabular}{|l|l|l|l|l|}
\hline & NRMSE & 0.068 & 0.041 & 0.197 \\
\hline
\end{tabular}

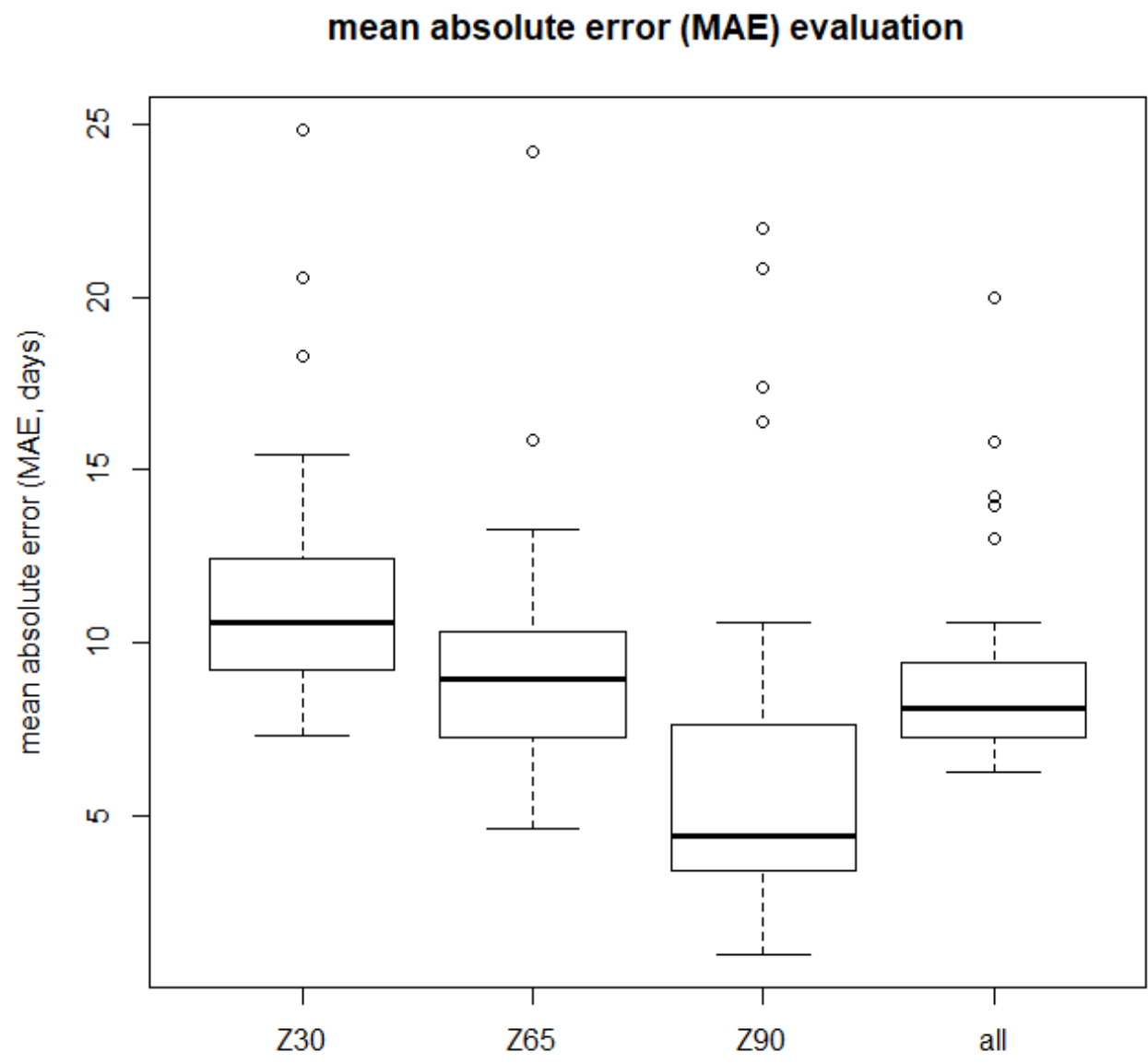

Figure 3

360 Boxes indicate the lower and upper quartiles. The solid line within the box is the median.

361 Whiskers indicate the most extreme data point which is no more than 1.5 times the

362 interquartile range from the box, and the outlier dots are those observations that are

363 beyond that range. 
367 EF value of the individual modeling groups, averaged over stages, was 0.51 , and $86 \%$ of the

368 modeling groups had $\mathrm{EF}>0$. The median skillT value of the individual modeling groups,

369 averaged over stages, was 0.20 , and $68 \%$ of the modeling groups had skillT $>0$.

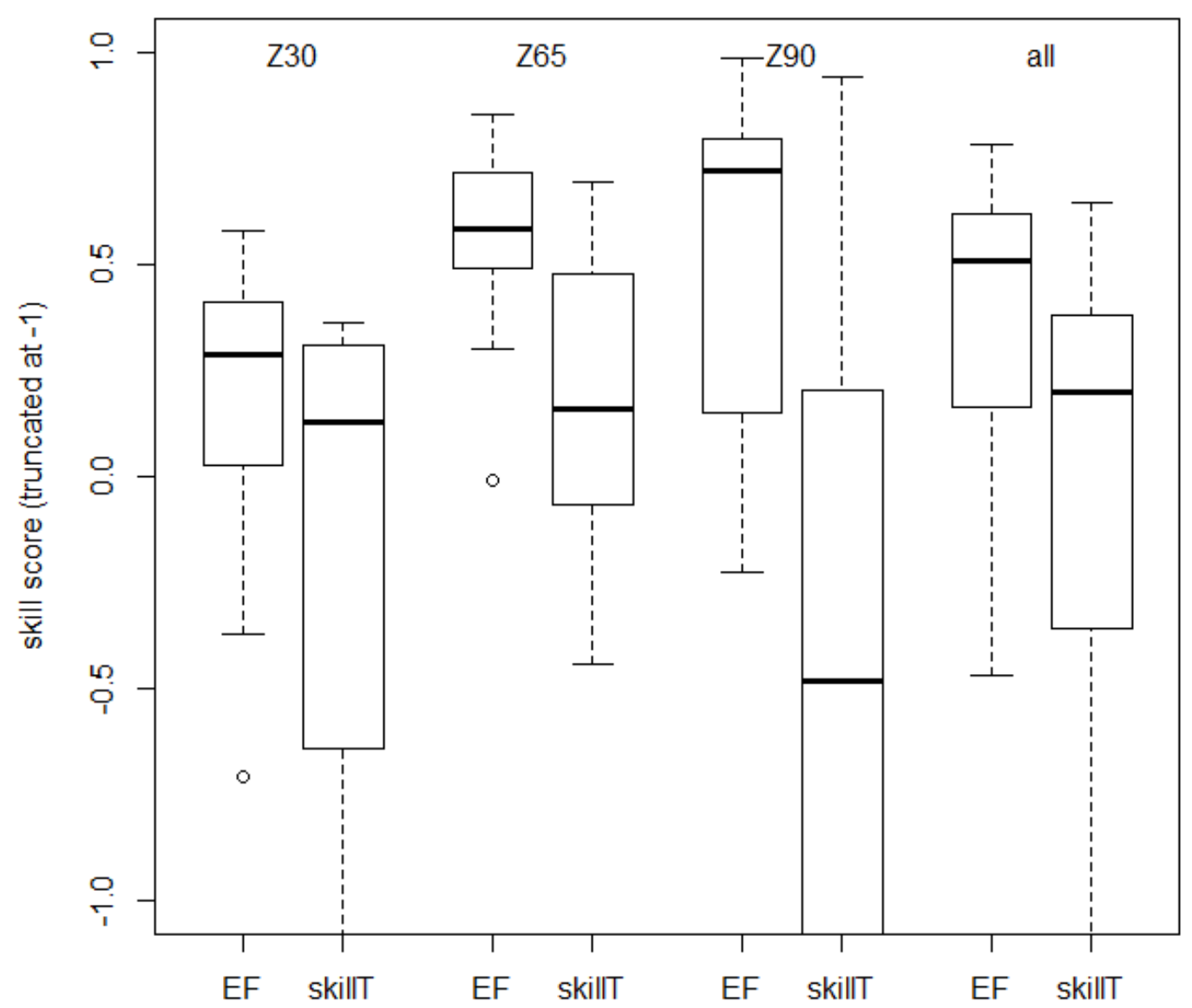


using the average number of degree days to each stage in the calibration data (skillT skill score). Boxes indicate the lower and upper quartiles. The solid line within the box is the median. Whiskers indicate the most extreme data point which is no more than $\mathbf{1 . 5}$ times the interquartile range from the box, and the outlier dots are those observations that are beyond that range. For readability the $y$ axis is cut off at -1 .

\subsection{Sources of variability} group were correlated. The calibration value explains $46 \%$ of the variability in the evaluation data $\left(\mathrm{R}^{2}=0.46\right)$.

There was substantial variability between modeling groups for each individual prediction, including between modeling groups that share the same model structure (Supplementary Figure S1). Averaged over the evaluation environments and over all three stages Z30, Z65, and Z90, the estimated within-structure standard deviation was 4.3 days and the estimated between-structure standard deviation was 11.9 days, so the within-structure standard deviation was $36 \%$ as large as the between-structure standard deviation.

\section{Discussion}

\subsection{Comparison of calibration and evaluation environments}

The calibration and evaluation environments were drawn from the same target population, namely wheat crops in the major wheat growing regions in Australia, with current 
climate and local management practices. We compared the calibration and evaluation environments for the main characteristics that are likely to affect phenology, namely temperature, day length, and accumulation of vernalizing temperatures. Temperatures and

environments, but the evaluation data had a larger range of day lengths than the calibration data.

This is the result of sampling variability, and may have led to larger prediction errors than if

404 the calibration data had a range of day lengths comparable to that of the evaluation data. calibration and evaluation data represent a similar range of conditions (with the caveat just

408 mentioned concerning photoperiod). This type of situation is of particular importance, for example, where one wants to calibrate a crop model using current conditions and subsequently test possible sowing dates within a limited range, or to compare phenology of multiple potential cultivars at specific sites within the calibration domain.

\subsection{Prediction error}

The evaluation here was based on data which had neither sites nor years in common

414 with the calibration data. This was thus a rigorous estimate of how well crop modeling groups can predict wheat phenology for unseen sites and weather, when provided with calibration data sampled from the target population. The median MAE among models averaged over phenology

417 stages was 9 days, which was substantially larger than the standard deviation of observed stages, 418 which was in the range 1-2 days. The best modeling group had an average MAE of 7 days, 419 which was still substantially larger than the standard deviation of observed stages. MAE values 420 were significantly larger for prediction of days to Z30 than for prediction of days to later Zadoks 421 stages. This may be due to the large variability between groups in predicting time to emergence, 
which is discussed in more detail below. Time to emergence is a major part of the time to Z30, but a smaller fraction of time to Z65 or Z90. phenology into account. In that study, the model was adjusted to some extent to the data used for evaluation, so the reported error probably underestimates the error for new environments. modeling groups here, for both the evaluation data (NRMSE here from 0.056 to 0.227 ) and the calibration data (NRMSE here from 0.041 to 0.197). Asseng et al. (2008), using the APSIM model, found RMSE of 4 days for wheat phenology predictions (mostly predictions of days to anthesis) for 44 different environments in Western Australia, a level of error which was smaller than the minimum RMSE of 9 days found here for the evaluation data, and even smaller than the minimum RMSE of 6 days found here for the calibration data. In that study, the phenology model was again adjusted to some extent to the data (S. Asseng, 2020, pers. comm.), which could explain the smaller errors.

The above comparisons suggest that prediction errors are very roughly similar between studies, but that there are differences depending on the details of the prediction problem and the way prediction error is evaluated. It is clearly useful to build up a knowledge base concerning phenology prediction error, as a baseline for comparison for future studies or even as a default value if evaluation is not done. Contributions to the knowledge base will be all the more useful, to the extent that the details of the prediction problem are clearly specified

443 (including whether it is of type interpolation or extrapolation and including a characterization 444 of the target population) and to the extent that the evaluation has a rigorous separation between 445 the predictor and the evaluation data. The present study should therefore be a valuable 446 contribution to such a knowledge base. 
It is of interest to compare the results here with those from a study structured like the present study (calibration and evaluation environments with similar characteristics, evaluation data not used for model development or tuning) but where the evaluation concerned prediction of two phenological stages of wheat in France, namely BBCH30 (equivalent to Z30) and BBCH55 (equivalent to Z55) (Wallach et al., 2019). To a large extent, the same modeling groups participated in both studies. Specifically, the French study included 27 different modeling groups, 26 of which participated in the present study. A comparison between the two studies gives an indication of variability in prediction error for the same modeling groups but for different target populations (Australian wheat in one case, French wheat in the other) and for somewhat different calibration data and predicted stages.

MAE averaged over the evaluation environments and over predicted stages ranged from the Australian data. The target population (wheat fields in Australia versus wheat fields in France) thus had a substantial effect on prediction errors. A detailed analysis of the underlying reasons for the larger errors in Australia is beyond the scope of this study. However, one possible contributing cause is the simulation of time to emergence. The average simulated time to emergence for all French environments was 10 days after sowing, and the mean standard deviation between modeling groups was 4 days. The corresponding values for the Australian environments were a mean emergence time of 15 days after sowing, and a mean standard 466 deviation between modeling groups of 18 days. This very large standard deviation for the 467 Australian environments, pointing at major differences between modeling groups, may be due to dry conditions in some environments and the uncertainty regarding initial soil conditions, 469 leading some models to simulate very long times to emergence (up to 107 days, Supplementary 470 Figure S1). This suggests that for Australian environments, it would be valuable to have 471 observations of time to emergence for calibration. It seems that for many modeling groups, it 
472

473

474

475

476

477

478

479

480

481

482

483

484

would be worthwhile to revisit the predictions of time to emergence under conditions like those of the Australian environments, taking advantage of specific modeling studies of time to emergence for wheat (Lindstrom et al., 1976; Wang et al., 2009).

An important question in modeling is whether the same modeling groups perform best for all target populations, or whether different groups are best for different target populations. There is quite a bit of scatter in the graph of MAE for the Australian versus French environments (Supplementary Fig. S2), but the rank correlation between the two (Kendall's tau) is 0.31 , which is statistically significant $(p=0.013)$. This suggests that there are modeling groups which perform better than others over a wide range of environments. Once again, it is prudent to repeat that this applies to the case where calibration is based on environments that are sampled from the target distribution. Prediction errors for extrapolation to conditions very different than those of the calibration data might behave very differently.

\subsection{Skill measures}

While prediction error is of course of interest, skill scores may be even more useful, as they indicate how models compare to alternative methods of prediction. Note that the EF skill score used here is somewhat different than the usual definition. Here, the naïve model is based solely on the calibration data, so this is in fact a feasible predictor. The more usual definition of the naïve model is the mean of all the data, including the data used for evaluation. Overall, all except four modeling groups had smaller MSE (were better predictors) than the naïve model.

The EF criterion is a rather low baseline for evaluating the usefulness of crop models for predicting phenology. Our second skill measure compares model MSE and MSE of the onlyT model, which assumes a constant number of degree days from sowing to each Zadoks stage, and estimates that number based on the calibration data. This should be a better predictor than the naïve model if photoperiod and vernalization effects are limited, and so is a more 
stringent test of usefulness of process models. We found that the onlyT model was indeed a better predictor than the naïve model. Nonetheless, 19 of the modeling groups performed better than the onlyT model. It seems that in most cases here, the added complexity in crop models beyond a simple sum of degree days is warranted. More generally, we suggest that systematically calculating a skill measure like skillT would give valuable information about the

501 usefulness of more complex models.

502

\subsection{Model averaging}

As found in many studies, e-median and e-mean had prediction errors comparable to the best modeling groups. This confirmed previous evidence and theoretical considerations showing that the use of e-mean or e-median is often a good strategy (Bassu et al., 2014; Palosuo et al., 2011; Rötter et al., 2012; Wallach et al., 2018). The e-mean model is based on a simple average over simulated values, so the results from every modeling group are weighted equally. An open question in using model ensembles is whether it would be better to give more weight to models that have smaller prediction errors for the calibration data (Christensen et al., 2010), for example using Bayesian Model Averaging (Wöhling et al., 2015). The results here show that phenology predictive performance for the calibration environments is significantly correlated with predictive performance for new environments. This was also found to be the case for a study evaluating phenology prediction by modeling groups based on phenology in French environments (Wallach et al., 2019) and suggests that in these cases, it may be worthwhile to use performance-weighted model ensembles. This may be due to the fact that in these studies, the calibration and evaluation environments were similar to one another. In cases where one is extrapolating to conditions quite different than those represented by the calibration environments, performance weighting may be less useful. This once again emphasizes that it is important to define for each evaluation study whether it is an evaluation of type "interpolation" or "extrapolation". 


\subsection{Sources of variability}

A major outcome of model ensemble studies is the variability in simulated values between modeling groups, which is an indication of the uncertainty of model-based predictions between model structures affect the simulated values. This however is difficult to untangle, given the multiple differences between structures. It seems that specific studies, for example modifying one specific aspect of multiple models, are needed to understand the various sources specific differences in model structure to differences in simulated results. However, it does allow us to separate two contributions to variability, namely the overall variability between model structures and the variability between different parameter values for the same model structure. An important question is the relative importance of the two, to determine priorities

534 for reducing overall uncertainty. Parameter uncertainty can arise from uncertainty in the default

536 (for example, the form of the objective function or the choice of parameters to estimate) and

537 from the values of the estimated parameters, which are uncertain because there is always a 538 limited amount of data. The within-structure variability here is a measure of the uncertainty due 539 to choice of default values and calibration approach, but not of uncertainty in the values of the 540 calibrated parameters. The within-structure standard deviation here is 4.3 days, compared to a 541 between-structure standard deviation (contribution of structure) of 11.9 days. The study based 542 on French environments found a within-structure standard deviation of 5.6 days and a between543 structure standard deviation of 8.0 days (Wallach et al., 2019). Confalonieri et al. (2016) also 544 found that the within-structure effect was in general, but not in all cases, smaller than the 545 between-structure effect on variability. 
Other studies have on the contrary focused on structural uncertainty versus uncertainty

547 in the calibrated parameters, without taking into account uncertainty in all the default parameter

548 values, nor uncertainty in the calibration approach chosen. Zhang et al. (2017) found that model

549 structure explained about $80 \%$ of the variability in simulated time to heading in rice and about

$55092 \%$ of the variability in simulated time to maturity in rice, the remainder of the variability

551 being due to parameter uncertainty. Wallach et al. (2017) found that model structure uncertainty

552 contributed about twice as much variance as parameter uncertainty to overall simulation

553 variance. It would be of interest to have a fuller treatment of parameter uncertainty, including

554 both different groups using the same model structure and an estimate of the uncertainty in the

555 parameters estimated by each group.

\section{Conclusions}

We evaluated how well 28 crop modeling groups simulate wheat phenology in Australia, in the case where both the calibration data and the evaluation data were sampled from

559 fields in the major wheat growing areas in Australia under current climate and local management. It is important to distinguish between interpolation type prediction, as here, and extrapolation type, since they are not evaluating the same properties of modeling groups. It is also important to emphasize that evaluation concerns both model structure and parameter values, and therefore the modeling group and not just the underlying model structure. MAE for

564 the evaluation data here ranged from 6 to 20 days depending on the modeling group, with a median of 9 days. About two thirds of the modeling groups performed better than a simple but relevant benchmark, which predicts phenology assuming a constant temperature sum for each

567 development stage. The added complexity of crop models beyond just the effect of temperature 568 is therefore justified in most cases. As found in many other studies, the multi-modeling group 569 mean and median had prediction errors nearly as small as the best modeling group, suggesting that using these ensemble predictors is a good strategy. Prediction errors for calibration and 
evaluation environments were found to be significantly correlated, which suggests that for interpolation type studies, it would be of interest to test ensemble predictors that weight individual models based on performance for the calibration data. The variability due to modeling group for a given model structure, which reflects part of parameter uncertainty, was found to be smaller than the variability due to model structure, but was not negligible. This implies that model improvement could be achieved not only by improving model structure but also by improving parameter values.

\section{Acknowledgements}

This work was in part supported by the Collaborative Research Center 1253 CAMPOS (Project 7: Stochastic Modelling Framework), funded by the German Research Foundation (DFG, Grant Agreement SFB 1253/1 2017), the Academy of Finland through projects AICropPro (316172 and 315896) and DivCSA (316215) and Natural Resources Institute Finland (Luke) through a strategic project BoostIA, the BonaRes projects "Soil3" (BOMA 03037514) and "I4S" (031B0513I) of the Federal Ministry of Education and Research (BMBF),

Germany, the Deutsche Forschungsgemeinschaft (DFG, German Research Foundation) under Germany's Excellence Strategy - EXC 2070 - 390732324, the project BiomassWeb of the GlobeE programme (Grant number: FKZ031A258B) funded by the Federal Ministry of Education and Research (BMBF, Germany), the EU funded SustEs project (CZ.02.1.01/0.0/0.0/16_019/0000797), the INRA ACCAF meta-programme, the German Federal Ministry of Education and Research (BMBF) in the framework of the funding measure "Soil as a Sustainable Resource for the Bioeconomy - BonaRes", project "BonaRes (Module B): BonaRes Centre for Soil Research, subproject B” (grant 031B0511B), the National Key Research and Development Program of China (2017YFD0300205), the 
595 National Science Foundation for Distinguished Young Scholars (31725020), the Priority

596 Academic Program Development of Jiangsu Higher Education Institutions (PAPD), the 111

597 project (B16026), and China Scholarship Council, the Agriculture and Agri-Food Canada's

598 Project 1387 under the Canadian Agricultural Partnership, the DFG Research Unit FOR 1695

599 'Agricultural Landscapes under Global Climate Change - Processes and Feedbacks on a

600 Regional Scale, the U.S. Department of Agriculture National Institute of Food and

601 Agriculture (award no. 2015-68007-23133) and USDA/NIFA HATCH grant N. MCL02368,

602 the National Key Research and Development Program of China (2016YFD0300105), The

603 Broadacre Agriculture Initiative, a research partnership between University of Southern

604 Queensland and the Queensland Department of Agriculture and Fisheries, the JPI FACCE

605 MACSUR2 project, funded by the Italian Ministry for Agricultural, Food, and Forestry

606 Policies (D.M. 24064/7303/15 of 26/Nov/2015). The field work was jointly funded by CSIRO

607 and the Grains Research and Development Corporation (GRDC) under the "Adding Value to

608 GRDC's National Variety Trial Network" project (CSA00027). The order in which the donors 609 are listed is arbitrary 


\section{References}

Andarzian, Bahram, Hoogenboom, G., Bannayan, M., Shirali, M., Andarzian, Behnam, 2015. Determining optimum sowing date of wheat using CSM-CERES-Wheat model. J. Saudi Soc. Agric. Sci. 14, 189-199. https://doi.org/10.1016/J.JSSAS.2014.04.004

Archontoulis, S. V., Miguez, F.E., Moore, K.J., 2014. A methodology and an optimization tool to calibrate phenology of short-day species included in the APSIM PLANT model: Application to soybean. Environ. Model. Softw. 62, 465-477. https://doi.org/10.1016/j.envsoft.2014.04.009

Asseng, S., Ewert, F., Rosenzweig, C., Jones, J.W., Hatfield, J.L., Ruane, A.C., Boote, K.J., Thorburn, P.J., Rötter, R.P., Cammarano, D., Brisson, N., Basso, B., Martre, P., Aggarwal, P.K., Angulo, C., Bertuzzi, P., Biernath, C., Challinor, A.J., Doltra, J., Gayler, S., Goldberg, R., Grant, R., Heng, L., Hooker, J., Hunt, L.A., Ingwersen, J., Izaurralde, R.C., Kersebaum, K.C., Müller, C., Naresh Kumar, S., Nendel, C., O’Leary, G., Olesen, J.E., Osborne, T.M., Palosuo, T., Priesack, E., Ripoche, D., Semenov, M.A., Shcherbak, I., Steduto, P., Stöckle, C., Stratonovitch, P., Streck, T., Supit, I., Tao, F., Travasso, M., Waha, K., Wallach, D., White, J.W., Williams, J.R., Wolf, J., 2013. Uncertainty in simulating wheat yields under climate change. Nat. Clim. Chang. 3, 827-832. https://doi.org/10.1038/nclimate1916

Asseng, S., Keating, B.A., Fillery, I.R.P., Gregory, P.J., Bowden, J.W., Turner, N.C., Palta, J.A., Abrecht, D.G., 2008. Performance of the APSIM-wheat model in Western Australia. F. Crop. Res. 57, 163-179.

Bao, Y., Hoogenboom, G., McClendon, R., Vellidis, G., 2017. A comparison of the performance of the CSM-CERES-Maize and EPIC models using maize variety trial data. Agric. Syst. 150, 109-119. https://doi.org/10.1016/J.AGSY.2016.10.006 
635 Bassu, S., Brisson, N., Durand, J.-L., Boote, K., Lizaso, J., Jones, J.W., Rosenzweig, C.,

636

637

638

639

640

641

642

643

644

645

646

647

648

649

650

651

652

653

654

655

656

657

658

Ruane, A.C., Adam, M., Baron, C., Basso, B., Biernath, C., Boogaard, H., Conijn, S., Corbeels, M., Deryng, D., De Sanctis, G., Gayler, S., Grassini, P., Hatfield, J., Hoek, S., Izaurralde, C., Jongschaap, R., Kemanian, A.R., Kersebaum, K.C., Kim, S.-H., Kumar, N.S., Makowski, D., Müller, C., Nendel, C., Priesack, E., Pravia, M.V., Sau, F., Shcherbak, I., Tao, F., Teixeira, E., Timlin, D., Waha, K., 2014. How do various maize crop models vary in their responses to climate change factors? Glob. Chang. Biol. 20, 2301-20. https://doi.org/10.1111/gcb.12520

Biernath, C., Gayler, S., Bittner, S., Klein, C., Högy, P., Fangmeier, A., Priesack, E., 2011. Evaluating the ability of four crop models to predict different environmental impacts on spring wheat grown in open-top chambers. Eur. J. Agron. 35, 71-82. https://doi.org/10.1016/j.eja.2011.04.001

Boote, K.J., Jones, J.W., Hoogenboom, G., 2008. Crop simulation models as tools for agroadvisories for weather and disease effects on production. J. Agrometeorol. 10, 9-17.

Boote, K.J., Jones, J.W., Hoogenboom, G., White, J.W., 2010. The Role of Crop Systems Simulation in Agriculture and Environment. Int. J. Agric. Environ. Inf. Syst. 1, 41-54.

Casella, G., Berger, R.L., 1990. Statistical Inference. Wadsworth and Brooks, Pacific Grove, CA.

Ceglar, A., van der Wijngaart, R., de Wit, A., Lecerf, R., Boogaard, H., Seguini, L., van den Berg, M., Toreti, A., Zampieri, M., Fumagalli, D., Baruth, B., 2019. Improving WOFOST model to simulate winter wheat phenology in Europe: Evaluation and effects on yield. Agric. Syst. 168, 168-180. https://doi.org/10.1016/J.AGSY.2018.05.002

Chauhan, Y.S., Ryan, M., Chandra, S., Sadras, V.O., 2019. Accounting for soil moisture improves prediction of flowering time in chickpea and wheat. Sci. Rep. 9, 7510. 
https://doi.org/10.1038/s41598-019-43848-6

660

661

662

663

664

665

666

667

668

669

670

671

672

673

674

675

676

Christensen, J., Kjellström, E., Giorgi, F., Lenderink, G., Rummukainen, M., 2010. Weight assignment in regional climate models. Clim. Res. 44, 179-194. https://doi.org/10.3354/cr00916

Confalonieri, R., Orlando, F., Paleari, L., Stella, T., Gilardelli, C., Movedi, E., Pagani, V., Cappelli, G., Vertemara, A., Alberti, L., Alberti, P., Atanassiu, S., Bonaiti, M., Cappelletti, G., Ceruti, M., Confalonieri, A., Corgatelli, G., Corti, P., Dell’Oro, M., Ghidoni, A., Lamarta, A., Maghini, A., Mambretti, M., Manchia, A., Massoni, G., Mutti, P., Pariani, S., Pasini, D., Pesenti, A., Pizzamiglio, G., Ravasio, A., Rea, A., Santorsola, D., Serafini, G., Slavazza, M., Acutis, M., 2016. Uncertainty in crop model predictions: What is the role of users? Environ. Model. Softw. 81, 165-173. https://doi.org/10.1016/j.envsoft.2016.04.009

Corripio, J.G., n.d. insol: Solar Radiation. R package version 1.2. 2019.

Efron, B., 1986. How Biased is the Apparent Error Rate of a Prediction Rule? J. Am. Stat. Assoc. 81, 461-470. https://doi.org/10.1080/01621459.1986.10478291

Flohr, B.M., Hunt, J.R., Kirkegaard, J.A., Evans, J.R., 2017. Water and temperature stress define the optimal flowering period for wheat in south-eastern Australia. F. Crop. Res. v. 209, 108-119. https://doi.org/10.1016/j.fcr.2017.04.012

Hussain, J., Khaliq, T., Ahmad, A., Akhtar, J., 2018. Performance of four crop model for simulations of wheat phenology, leaf growth, biomass and yield across planting dates. PLoS One 13, e0197546. https://doi.org/10.1371/journal.pone.0197546

Johnen, T., Boettcher, U., Kage, H., 2012. A variable thermal time of the double ridge to flag leaf emergence phase improves the predictive quality of a CERES-Wheat type 
phenology model. Comput. Electron. Agric. 89, 62-69. https://doi.org/10.1016/J.COMPAG.2012.08.002

Kumudini, S., Andrade, F.H., Boote, K.J., Brown, G.A., Dzotsi, K.A., Edmeades, G.O., Gocken, T., Goodwin, M., Halter, A.L., Hammer, G.L., Hatfield, J.L., Jones, J.W., Kemanian, A.R., Kim, S.-H., Kiniry, J., Lizaso, J.I., Nendel, C., Nielsen, R.L., Parent, B., Stöckle, C.O., Tardieu, F., Thomison, P.R., Timlin, D.J., Vyn, T.J., Wallach, D., Yang, H.S., Tollenaar, M., 2014. Predicting maize phenology: Intercomparison of functions for developmental response to temperature. Agron. J. 106, 2087-2097. https://doi.org/10.2134/agronj14.0200

Lawes, R.A., Huth, N.D., Hochman, Z., 2016. Commercially available wheat cultivars are broadly adapted to location and time of sowing in Australia's grain zone. Eur. J. Agron. 77, 38-46. https://doi.org/10.1016/J.EJA.2016.03.009

Lindstrom, M.J., Papendick, R.I., Koehler, F.E., 1976. A Model to Predict Winter Wheat Emergence as Affected by Soil Temperature, Water Potential, and Depth of Planting1. Agron. J. 68, 137-141. https://doi.org/10.2134/agronj1976.00021962006800010038x

Luo, Q., O’Leary, G., Cleverly, J., Eamus, D., 2018. Effectiveness of time of sowing and cultivar choice for managing climate change: wheat crop phenology and water use efficiency. Int. J. Biometeorol. 62, 1049-1061. https://doi.org/10.1007/s00484-018$1508-4$

Maiorano, A., Martre, P., Asseng, S., Ewert, F., Müller, C., Rötter, R.P., Ruane, A.C., Semenov, M.A., Wallach, D., Wang, E., Alderman, P.D., Kassie, B.T., Biernath, C., Basso, B., Cammarano, D., Challinor, A.J., Doltra, J., Dumont, B., Rezaei, E.E., Gayler, S., Kersebaum, K.C., Kimball, B.A., Koehler, A.-K., Liu, B., O’Leary, G.J., Olesen, J.E., Ottman, M.J., Priesack, E., Reynolds, M., Stratonovitch, P., Streck, T., Thorburn, P.J., 
Waha, K., Wall, G.W., White, J.W., Zhao, Z., Zhu, Y., 2016. Crop model improvement reduces the uncertainty of the response to temperature of multi-model ensembles. F. Crop. Res. https://doi.org/10.1016/j.fcr.2016.05.001

McCuen, R.H., Knight, Z., Cutter, A.G., 2006. Evaluation of the Nash-Sutcliffe Efficiency Index. J. Hydrol. Eng. 11, 597-602. https://doi.org/10.1061/(ASCE)1084-

Palosuo, T., Kersebaum, K.C., Angulo, C., Hlavinka, P., Moriondo, M., Olesen, J.E., Patil, 0699(2006)11:6(597) R.H., Ruget, F., Rumbaur, C., Takáč, J., Trnka, M., Bindi, M., Çaldă̆, B., Ewert, F., Ferrise, R., Mirschel, W., Şaylan, L., Šiška, B., Rötter, R., 2011. Simulation of winter wheat yield and its variability in different climates of Europe: A comparison of eight crop growth models. Eur. J. Agron. 35, 103-114. https://doi.org/10.1016/j.eja.2011.05.001

Rötter, R.P., Palosuo, T., Kersebaum, K.C., Angulo, C., Bindi, M., Ewert, F., Ferrise, R., Hlavinka, P., Moriondo, M., Nendel, C., Olesen, J.E., Patil, R.H., Ruget, F., Takáč, J., Trnka, M., 2012. Simulation of spring barley yield in different climatic zones of

Sadras, V.O., Monzon, J.P., 2006. Modelled wheat phenology captures rising temperature trends: Shortened time to flowering and maturity in Australia and Argentina. F. Crop. Res. 99, 136-146. https://doi.org/10.1016/J.FCR.2006.04.003 Yadav, K., Huete, A., 2018. A 30-m landsat-derived cropland extent product of Australia and China using random forest machine learning algorithm on Google Earth Engine 
cloud computing platform. ISPRS J. Photogramm. Remote Sens. 144, 325-340. https://doi.org/10.1016/J.ISPRSJPRS.2018.07.017

732

van Bussel, L.G.J., Stehfest, E., Siebert, S., Müller, C., Ewert, F., 2015. Simulation of the phenological development of wheat and maize at the global scale. Glob. Ecol. Biogeogr. 24, 1018-1029. https://doi.org/10.1111/geb.12351

Wallach, D., Martre, P., Liu, B., Asseng, S., Ewert, F., Thorburn, P.J., van Ittersum, M., Aggarwal, P.K., Ahmed, M., Basso, B., Biernath, C., Cammarano, D., Challinor, A.J., De Sanctis, G., Dumont, B., Eyshi Rezaei, E., Fereres, E., Fitzgerald, G.J., Gao, Y., Garcia-Vila, M., Gayler, S., Girousse, C., Hoogenboom, G., Horan, H., Izaurralde, R.C., Jones, C.D., Kassie, B.T., Kersebaum, K.C., Klein, C., Koehler, A.-K., Maiorano, A., Minoli, S., Müller, C., Naresh Kumar, S., Nendel, C., O’Leary, G.J., Palosuo, T., Priesack, E., Ripoche, D., Rötter, R.P., Semenov, M.A., Stöckle, C., Stratonovitch, P., Streck, T., Supit, I., Tao, F., Wolf, J., Zhang, Z., 2018. Multimodel ensembles improve predictions of crop-environment-management interactions. Glob. Chang. Biol. 24, 50725083. https://doi.org/10.1111/gcb.14411

Wallach, D., Nissanka, S.P., Karunaratne, A.S., Weerakoon, W.M.W., Thorburn, P.J., Boote, K.J., Jones, J.W., 2017. Accounting for both parameter and model structure uncertainty in crop model predictions of phenology: A case study on rice. Eur. J. Agron. 88. https://doi.org/10.1016/j.eja.2016.05.013

Wallach, D., Palosuo, T., Thorburn, P., Seidel, S.J., Gourdain, E., Asseng, S., Basso, B., Buis, S., Crout, N.M.J., Dibari, C., Dumont, B., Ferrise, R., Gaiser, T., Garcia, C., Gayler, S., Ghahramani, A., Hochman, Z., Hoek, S., Horan, H., Hoogenboom, G., Huang, M., Jabloun, M., Jing, Q., Justes, E., Kersebaum, K.C., Klosterhalfen, A., Launay, M., Luo, Q., Maestrini, B., Mielenz, H., Moriondo, M., Nariman Zadeh, H., Olesen, J.E., Poyda, 
A., Priesack, E., Pullens, J.W.M., Qian, B., Schütze, N., Shelia, V., Souissi, A., Specka, X., Srivastava, A.K., Stella, T., Streck, T., Trombi, G., Wallor, E., Wang, J., Weber, T.K.D., Weihermüller, L., de Wit, A., Wöhling, T., Xiao, L., Zhao, C., Zhu, Y., 2019. How well do crop models predict phenology, given calibration data from the target population? bioRxiv 708578. https://doi.org/10.1101/708578

Wang, E., Martre, P., Zhao, Z., Ewert, F., Maiorano, A., Rötter, R.P., Kimball, B.A., Ottman, M.J., Wall, G.W., White, J.W., Reynolds, M.P., Alderman, P.D., Aggarwal, P.K., Anothai, J., Basso, B., Biernath, C., Cammarano, D., Challinor, A.J., De Sanctis, G., Doltra, J., Fereres, E., Garcia-Vila, M., Gayler, S., Hoogenboom, G., Hunt, L.A., Izaurralde, R.C., Jabloun, M., Jones, C.D., Kersebaum, K.C., Koehler, A.-K., Liu, L., Müller, C., Naresh Kumar, S., Nendel, C., O’Leary, G., Olesen, J.E., Palosuo, T., Priesack, E., Eyshi Rezaei, E., Ripoche, D., Ruane, A.C., Semenov, M.A., Shcherbak, I., Stöckle, C., Stratonovitch, P., Streck, T., Supit, I., Tao, F., Thorburn, P., Waha, K., Wallach, D., Wang, Z., Wolf, J., Zhu, Y., Asseng, S., 2017. The uncertainty of crop yield projections is reduced by improved temperature response functions. Nat. Plants $3,1-13$. https://doi.org/10.1038/nplants.2017.102

Wang, H., Cutforth, H., McCaig, T., McLeod, G., Brandt, K., Lemke, R., Goddard, T., Sprout, C., 2009. Predicting the time to 50\% seedling emergence in wheat using a Beta model. NJAS - Wageningen J. Life Sci. 57, 65-71. https://doi.org/https://doi.org/10.1016/j.njas.2009.07.003

Willmott, C.J., Matsuura, K., 2005. Advantages of the mean absolute error (MAE) over the root mean square error (RMSE) in assessing average model performance. Clim. Res. 30, 79-82. 
explore the worth of data for soil-plant model selection and prediction. Water Resour.

Workman, D., 2020. Worldstopexports [WWW Document]. URL http://www.worldstopexports.com/wheat-exports-country/ (accessed 3.10.20).

Yuan, S., Peng, S., Li, T., 2017. Evaluation and application of the ORYZA rice model under different crop managements with high-yielding rice cultivars in central China. F. Crop. Res. 212, 115-125. https://doi.org/10.1016/J.FCR.2017.07.010 cereals. Weed Res. 14, 415-421. https://doi.org/10.1111/j.1365-3180.1974.tb01084.x model parameters in simulating rice phenology in China. Eur. J. Agron. 87, 30-39. https://doi.org/10.1016/j.eja.2017.04.004 


\section{SUPPLEMENTARY}

\section{Table S1}

Model structures used in this study

\begin{tabular}{|l|l|l|}
\hline Model structure & Version(s) & References \\
\hline AgroC & May2018 & $\begin{array}{l}\text { Herbst M., Hellebrand H.J., Bauer J., Huisman J.A., Simůnek J., Weihermüller L., Graf A., } \\
\text { Vanderborght J., Vereecken H. (2008). Multiyear heterotrophic soil respiration: Evaluation of a } \\
\text { coupled CO } 2 \text { transport and carbon turnover model. Ecological Modelling. 214: 271-283. } \\
\text { Klosterhalfen, A., Herbst M., Weihermüller L., Graf A., Schmidt M., Stadler A., Schneider K., } \\
\text { Subke J.-A., Huisman J.A., Vereecken H. (2017). Multi-site calibration and validation of a net } \\
\text { ecosystem carbon exchange model for croplands. Ecological Modelling. 363: 137-156. }\end{array}$ \\
\hline APSIM & $7.8,7.9,7.10$ & $\begin{array}{l}\text { Keating B.A., P.S. Carberry, G.L. Hammer, M.E. Probert, M.J. Robertson, D. Holzworth, N.I. } \\
\text { Huth, J.N.G. Hargreaves, H. Meinke, Z. Hochman, G. McLean, K. Verburg, V. Snow, J.P. } \\
\text { Dimes, M. Silburn, E. Wang, S. Brown, K.L. Bristow, S. Asseng, S. Chapman, R.L. McCown, } \\
\text { D.M. Freebairn and C.J.Smith. (2003). An overview of APSIM, a model designed for farming } \\
\text { systems simulation. European Journal of Agronomy 18: 267-288. } \\
\text { Holzworth D.P., Huth N.I., DeVoil P.G. et al. (2014) APSIM - Evolution towards a new } \\
\text { generation of agricultural systems simulation. Environmental Modelling \& Software, 62, 327- } \\
350\end{array}$ \\
\hline AquaCrop & 4.0 & $\begin{array}{l}\text { Vanuytrecht E., Raes D., Steduto P., Hsiao T.C., Fereres E., Heng L.K., Garcia Vila M., Mejias } \\
\text { Moreno, P. (2014). AquaCrop: FAO'S crop water productivity and yield response model. } \\
\text { Environmental Modelling \& Software, 62: 351-360 }\end{array}$ \\
\hline
\end{tabular}




\begin{tabular}{|c|c|c|}
\hline CERES-Wheat & $\begin{array}{l}\text { DSSATV4.7,V } \\
\text { 4.7., Expert-N } \\
3.0\end{array}$ & $\begin{array}{l}\text { Hoogenboom, G., C.H. Porter, K.J. Boote, V. Shelia, P.W. Wilkens, U. Singh, J.W. White, S. } \\
\text { Asseng, J.I. Lizaso, L.P. Moreno, W. Pavan, R. Ogoshi, L.A. Hunt, G.Y. Tsuji, and J.W. Jones. } \\
\text { 2019. The DSSAT crop modeling ecosystem. In: p.173-216 [K.J. Boote, editor] Advances in } \\
\text { Crop Modeling for a Sustainable Agriculture. Burleigh Dodds Science Publishing, Cambridge, } \\
\text { United Kingdom (http://dx.doi.org/10.19103/AS.2019.0061.10). } \\
\text { Hoogenboom, G., C.H. Porter, V. Shelia, K.J. Boote, U. Singh, J.W. White, L.A. Hunt, R. } \\
\text { Ogoshi, J.I. Lizaso, J. Koo, S. Asseng, A. Singels, L.P. Moreno, and J.W. Jones. 2019. Decision } \\
\text { Support System for Agrotechnology Transfer (DSSAT) Version } 4.7 \text { (www.DSSAT.net). DSSAT } \\
\text { Foundation, Gainesville, Florida, USA. }\end{array}$ \\
\hline CoupModel & Version 5.4 .4 & $\begin{array}{l}\text { Coucheney E, Eckersten H, Hoffmann H, Jansson PE, Gaiser T, Ewert F, Lewan E. 2018. Key } \\
\text { functional soil types explain data aggregation effects on simulated yield, soil carbon, drainage } \\
\text { and nitrogen leaching at a regional scale. Geoderma, 318: 167-181. DOI: } \\
\text { 10.1016/j.geoderma.2017.11.025.Jansson, P-E. (2012). CoupModel: model use, calibration, and } \\
\text { validation. Transactions of the ASABE, } 55 \text { (4):1337-1344. (American Society of Agricultural and } \\
\text { Biological Engineers). } \\
\text { Senapati, N., Jansson, P-E., Smith, P., Chabbi, A. (2016). Modelling heat, water and carbon } \\
\text { fluxes in mown grassland under multi-objective and multi-criteria constraints. Environmental } \\
\text { modelling \& software, 80: } 201-224 \text {. }\end{array}$ \\
\hline CROPSIM-Wheat & DSSAT V4.7 & $\begin{array}{l}\text { Hoogenboom G., Porter C. H., Shelia V., Boote K. J., Singh U., White J. W., Hunt L. A., Ogoshi } \\
\text { R., Lizaso J. I., Koo J., Asseng S., Singels A., L.P. Moreno, Jones J. W. (2017). Decision }\end{array}$ \\
\hline
\end{tabular}




\begin{tabular}{|c|c|c|}
\hline & & $\begin{array}{l}\text { Support System For Agrotechnology Transfer (DSSAT). Version 4.7. DSSAT Foundation, } \\
\text { Gainesville, Florida, USA. }\end{array}$ \\
\hline Cropsyst & 3.04 .08 & $\begin{array}{l}\text { Stöckle C. O., Donatelli M., Nelson R. (2003). CropSyst, a cropping systems simulation } \\
\text { model. European Journal of Agronomy, 18(3-4), 289-307. }\end{array}$ \\
\hline DAISY & 5.59 & $\begin{array}{l}\text { Hansen S., P. Abrahamsen C. T. Petersen, Styczen M.. (2012). Daisy: Model Use, Calibration, } \\
\text { and Validation. Transactions of the ASABE, 55, 1317-1335. }\end{array}$ \\
\hline Nwheat & DSSAT & $\begin{array}{l}\text { Kassie B.T., Asseng S., Porter C.H. and Royce F.S. (2016). Performance of DSSAT-Nwheat } \\
\text { across a wide range of current and future growing conditions. European Journal of Agronomy, } \\
81,27-36 \text {. }\end{array}$ \\
\hline GECROS & Expert-N 3.0 & $\begin{array}{l}\text { Yin X., van Laar H. H. (2005). Crop systems dynamics. An ecophysiological simulation model } \\
\text { for genotype-by-environment interactions. Wageningen Academic Publishers, } 155 \text { pp., } \\
\text { Wageningen, The Netherlands. }\end{array}$ \\
\hline HERMES & 4.27 & $\begin{array}{l}\text { Kersebaum K.C. (2007). Modelling nitrogen dynamics in soil-crop systems with HERMES. } \\
\text { Nutrient Cycling in Agroecosystems, 77, 39-52. } \\
\text { Kersebaum K.C. (2011). Special features of the HERMES model and additional procedures for } \\
\text { parameterization, calibration, validation, and applications In: L.R. Ahuja and L. Ma (ed.): } \\
\text { Advances in Agricultural Systems Modeling Series 2. 65-94. ASA, CSSA, SSSA, Madison, } \\
\text { USA. }\end{array}$ \\
\hline LINTUL & LINTUL5 & $\begin{array}{l}\text { Wolf J. (2012). User guide for LINTUL5: Simple generic model for simulation of crop growth } \\
\text { under potential, water limited and nitrogen, phosphorus and potassium limited conditions. } \\
\text { Wageningen UR. }\end{array}$ \\
\hline
\end{tabular}




\begin{tabular}{|c|c|c|}
\hline MONICA & 2.02 & $\begin{array}{l}\text { Nendel C., Berg M., Kersebaum K.C., Mirschel W., Specka X., Wegehenkel M., Wenkel K.O., } \\
\text { Wieland R. (2011). The MONICA model: Testing predictability for crop growth, soil moisture } \\
\text { and nitrogen dynamics. Ecological Modelling 222(9), } 1614 \text { - } 1625 \text {. } \\
\text { Specka X., Nendel C., Wieland R. (2015). Analysing the parameter sensitivity of the agro- } \\
\text { ecosystem model MONICA for different crops. European Journal of Agronomy, 71, 73-87. } \\
\text { Specka X., Nendel C., Wieland R. (2019). Temporal Sensitivity Analysis of the MONICA } \\
\text { Model: Application of Two Global Approaches to Analyze the Dynamics of Parameter } \\
\text { Sensitivity. Agriculture 9(2), } 37 .\end{array}$ \\
\hline OpenCrop & & $\begin{array}{l}\text { OpenCrop: An Open Source Crop Model - Model Description. Crout NMJ, Karanaratne, A \& } \\
\text { Jabloun, M (2018). School of Biosciences, University of Nottingham, UK }\end{array}$ \\
\hline PANORAMIX & $\mathrm{R}$ version & $\begin{array}{l}\text { Gate, P., 1995. Écophysiologie du blé. Lavoisier-Technique et documentation. } \\
\text { Chatelin, M.H., Aubry, C., Poussin, J.C., Meynard, J.M., Massé, J., Verjux, N., Gate, P., Le Bris, } \\
\text { X., 2005. DéciBlé, a software package for wheat crop management simulation. Agric. Syst. 83, } \\
\text { 77-99. https://doi.org/10.1016/J.AGSY.2004.03.003 }\end{array}$ \\
\hline Salus & & $\begin{array}{l}\text { Basso B, Ritchie JT, Grace PR, Sartori L (2006) Simulation of tillage systems impact on soil } \\
\text { biophysical properties using the SALUS model. Italian Journal of Agronomy,1, 677-688. } \\
\text { Basso B. and J.T. Ritchie. 2015. Simulating Crop Growth and Biogeochemical Fluxes in } \\
\text { Response to Land Management using the SALUS Model. In S. K. Hamilton, J. E. Doll, and G. } \\
\text { P. Robertson, editors. The ecology of agricultural landscapes: long-term research on the path to } \\
\text { sustainability. Oxford University Press, New York, NY USA }\end{array}$ \\
\hline SPASS & Expert-N 3.0 & $\begin{array}{l}\text { Wang, E. (1997). Development of a Generic Process-Oriented Model for Simulation of Crop } \\
\text { Growth. München, Herbert Utz Verlag Wissenschaft. } 195 \text { pp. }\end{array}$ \\
\hline
\end{tabular}




\begin{tabular}{|c|c|c|}
\hline SSM-Wheat & & $\begin{array}{l}\text { Soltani A., Maddah V., Sinclair T. (2013). SSM-Wheat: a simulation model for wheat } \\
\text { development, growth and yield. International Journal of Plant Production, 7, 711-740. }\end{array}$ \\
\hline STICS & 8_5_0 & $\begin{array}{l}\text { Brisson N., Launay M., Mary B., Beaudoin N. (2009). Conceptual basis, formalisations and } \\
\text { parametrization of the STICS crop model. Quae, 304pp } \\
\text { Coucheney E., Buis S., Launay M. Constantin J., Mary B., Garcia de Cortazar-Atauri I., Ripoche } \\
\text { D., Beaudoin N., Ruget F., Andrianorisoa S., Le Bas C., Justes E., Léonard J. (2015). Accuracy, } \\
\text { robustness and behavior of the STICS } 8.2 .2 \text { soil-crop model for plant, water and nitrogen } \\
\text { outputs: evaluation over a wide range of agro-environmental conditions in France. } \\
\text { Environmental Modelling \& Software, 64, 177-190 }\end{array}$ \\
\hline SUCROS & Expert-N 3.0 & $\begin{array}{l}\text { van Laar, H.H., J. Goudriaan, und H. van Keulen, 1992: Simulation of crop growth for potential } \\
\text { and water-limited production situations (as applied to spring wheat).: Simulation Report CABO- } \\
\text { TT no. 27. Wageningen: Centre for Agrobiological Research and Department of Theoretical } \\
\text { Production Ecology, Wageningen Agricultural University; } \\
\text { Vanclooster, M., Viaene P., Diels J., Christiaens K., 1994: WAVE a mathematical model for } \\
\text { simulating water and agrochemicals in the soil and vadose environment. Reference and user's } \\
\text { manual (release 2.0). Leuven: Institute for Land and Water Management, Katholieke Universiteit } \\
\text { Leuven. }\end{array}$ \\
\hline PCWOFOST & 5.3 .3 & $\begin{array}{l}\text { Ceglar A., van der Wijngaart R., de Wit A., Lecerf R., Boogaard H., Seguini L., van den Berg M., } \\
\text { Toreti A., Zampieri M., Fumagalli D., Baruth B. (2019). Improving WOFOST model to simulate winter } \\
\text { wheat phenology in Europe: Evaluation and effects on yield. Agricultural Systems. 168, 168-180. }\end{array}$ \\
\hline WCCWOFOST & 7.1 .7 & $\begin{array}{l}\text { Boogaard, H.L., Van Diepen, C.A., Rötter, R.P., Cabrera, J.M.C.A., Van Laar, H.H., } 1998 . \\
\text { User's guide for the WOFOST } 7.1 \text { crop growth simulation model and WOFOST control center } \\
\text { 1.5. Technical Document 52. Winand Staring Centre, Wageningen, the Netherlands, } 144 \text { pp. }\end{array}$ \\
\hline
\end{tabular}




\begin{tabular}{|l|l|l|}
\hline Wheat-Grow & $\begin{array}{l}\text { Zhu Y.; Liu L.; Liu, B. WheatGrow: A simulation model for predicting growth and productivity } \\
\text { in wheat. In Proceedings of the Workshop on Modeling Wheat Response to High Temperature, } \\
\text { Texcoco, Mexico, 19-21 June 2013. } \\
\text { Lv Z., Liu X., Tang L., Liu, L., Cao, W. and Zhu, Y., 2016. Estimation of ecotype-specific } \\
\text { cultivar parameters in a wheat phenology model and uncertainty analysis. Agricultural and } \\
\text { Forest Meteorology, 221: 219-229. }\end{array}$ \\
\hline
\end{tabular}




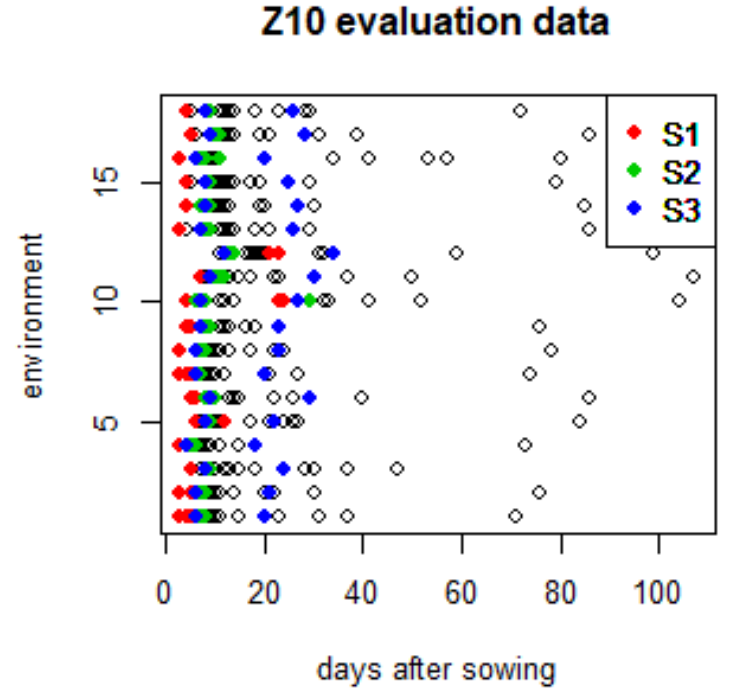

Z65 evaluation data

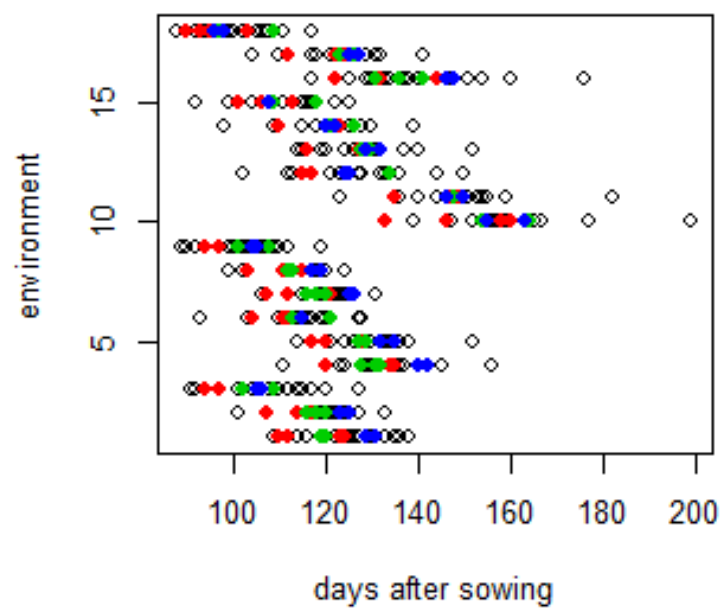

Z30 evaluation data

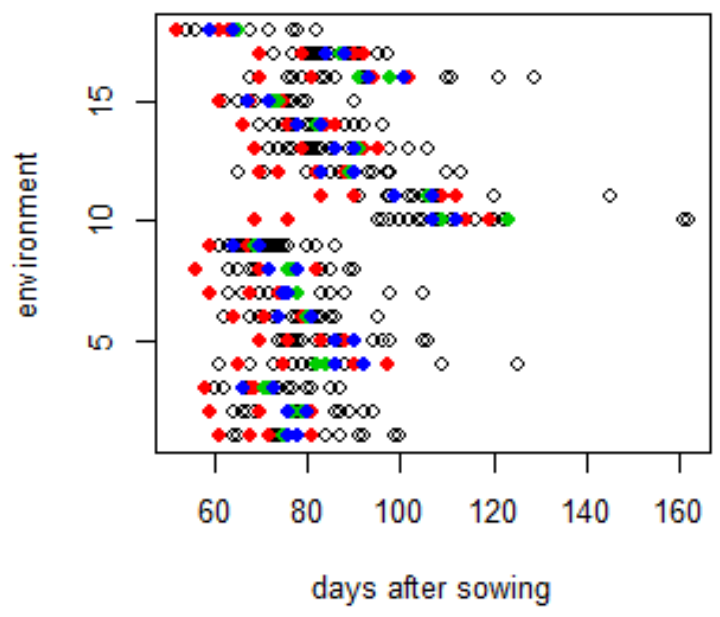

Z90 evaluation data

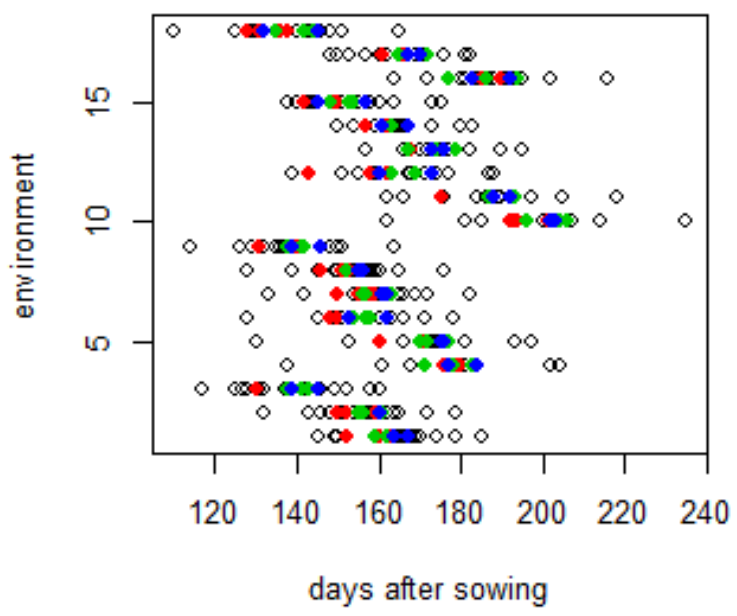

Figure S1

Predictions of days from sowing to Zadoks stages Z10 (emergence), Z30, Z65 and Z90 by each modeling group for each evaluation environment. Modeling groups that used the same model structure are identified by color (red for structure S1, green for structure S2, blue for structure S3). 


\section{Table S2}

Prediction errors for each modeling group and for the models e-mean, e-median, naive and onlyT. The columns are and Z90 for the evaluation environments (days), root mean squared error (RMSE) averaged over the stages Z30, Z65 and Z90 for the evaluation environments (days), the skill measures EF and skillT averaged over the stages Z30, Z65 and Z90 for the evaluation environments (unitless) and MAE averaged over the stages Z30, Z65 and Z90 for the calibration environments

811 (days). The models are ordered by average MAE (value in first column). NA indicates that that modeling group didn't predict

812 the time to the indicated stage.

\begin{tabular}{|c|c|c|c|c|c|c|c|c|}
\hline & _eval MAE & $\begin{array}{ll}\text { MAE } \\
\text { Z30 }\end{array}$ & Z65 & Z 290 MAE & $\begin{array}{ll} & \text { RMSE } \\
\text { _eval } & \end{array}$ & eval $\quad F_{-}$ & _eval ${ }^{\text {skillT }}$ & E_cal ${ }^{\text {MA }}$ \\
\hline M9 & 6.3 & NA & 9.3 & 3.2 & 7.2 & 0.7 & 0.489 & 6.2 \\
\hline an & 6.3 & 8.8 & 7.3 & 2.9 & 8.1 & $\begin{array}{r}0.6 \\
4 \\
\end{array}$ & 0.38 & 6 \\
\hline M24 & 6.4 & 9 & 6.8 & 3.2 & 8.6 & $\begin{array}{r}0.6 \\
2\end{array}$ & 0.351 & 8.5 \\
\hline dian eme & 6.4 & 8.6 & 7.4 & 3.3 & 8.3 & $\begin{array}{r}0.6 \\
3 \\
\end{array}$ & 0.367 & 5.9 \\
\hline M21 & 6.6 & 8.7 & 6.6 & 4.4 & 8.5 & $\begin{array}{r}0.6 \\
4 \\
\end{array}$ & 0.379 & 5.9 \\
\hline M4 & 6.7 & 9.8 & 6.4 & 3.8 & 8.4 & $\begin{array}{r}0.6 \\
5 \\
\end{array}$ & 0.39 & 5.7 \\
\hline $\mathrm{M} 2$ & 6.8 & 10.4 & 7.3 & 2.8 & 8.8 & $\begin{array}{r}0.5 \\
7 \\
\end{array}$ & 0.263 & 6.3 \\
\hline M13 & 7.2 & 10.6 & 7.9 & 3.2 & 9 & $\begin{array}{r}0.5 \\
5 \\
\end{array}$ & 0.231 & 8.3 \\
\hline M18 & 7.2 & NA & 10.8 & 3.6 & 8.6 & $\begin{array}{r}0.6 \\
2 \\
\end{array}$ & 0.336 & 7.7 \\
\hline M15 & 7.3 & 11.7 & 4.6 & 5.6 & 8.5 & $\begin{array}{r}0.6 \\
4 \\
\end{array}$ & 0.383 & 8 \\
\hline
\end{tabular}




\begin{tabular}{|c|c|c|c|c|c|c|c|c|}
\hline M11 & 7.3 & 7.7 & 7.4 & 6.8 & 10 & $\begin{array}{r}0.5 \\
3\end{array}$ & 0.18 & 9 \\
\hline M25 & 7.4 & 10.7 & 6.7 & 4.8 & 8.9 & 0.6 & 0.307 & 6.1 \\
\hline $\mathrm{M} 23$ & 7.8 & 10.6 & 8.5 & 4.2 & 10 & 0.5 & 0.14 & 6.7 \\
\hline M26 & 7.9 & 9.3 & 10.3 & 4.2 & 10.3 & $\begin{array}{r}0.4 \\
7 \\
\end{array}$ & 0.082 & 7.4 \\
\hline M3 & 8 & NA & 10.1 & 6 & 9 & $\begin{array}{r}0.6 \\
1 \\
\end{array}$ & 0.322 & 7.7 \\
\hline M27 & 8 & 9.7 & 10.9 & 3.4 & 10.1 & $\begin{array}{r}0.4 \\
6 \\
\end{array}$ & 0.066 & 6.7 \\
\hline M29 & 8.2 & 8.2 & 8.1 & NA & 11.2 & $\begin{array}{r}0.4 \\
4 \\
\end{array}$ & 0.029 & 9.7 \\
\hline only & 8.2 & 10.7 & 10.6 & 3.2 & 10.5 & $\begin{array}{r}0.4 \\
2 \\
\end{array}$ & 0 & 8 \\
\hline M17 & 8.4 & 7.3 & 7.3 & 10.6 & 10.4 & $\begin{array}{r}0.5 \\
2 \\
\end{array}$ & 0.165 & 7 \\
\hline M19 & 8.5 & 11.4 & 10.2 & 3.8 & 10.4 & $\begin{array}{r}0.4 \\
4 \\
\end{array}$ & 0.032 & 7.9 \\
\hline M12 & 9.3 & 12.4 & 7.3 & 8 & 11.4 & $\begin{array}{r}0.3 \\
9 \\
\end{array}$ & $\begin{array}{r}- \\
0.058 \\
\end{array}$ & 8.1 \\
\hline M7 & 9.3 & 15.4 & 9 & 3.4 & 11.5 & $\begin{array}{r}0.2 \\
3 \\
\end{array}$ & $\begin{array}{r}- \\
0.323 \\
\end{array}$ & 13.3 \\
\hline M20 & 9.3 & NA & 11.5 & 7.2 & 11.4 & 0.4 & $\begin{array}{r}- \\
0.041 \\
\end{array}$ & 8.3 \\
\hline M8 & 9.4 & 12.4 & 8.8 & 6.8 & 11.6 & $\begin{array}{r}0.3 \\
5 \\
\end{array}$ & $\begin{array}{r}- \\
0.117 \\
\end{array}$ & 12 \\
\hline $\mathrm{M} 22$ & 9.5 & 9.1 & 15.8 & 3.4 & 12.1 & $\begin{array}{r}0.2 \\
1 \\
\end{array}$ & $\begin{array}{r}- \\
0.362 \\
\end{array}$ & 7.3 \\
\hline M10 & 10.6 & 24.8 & 5.9 & 1 & 13.3 & $\begin{array}{r}- \\
0.54\end{array}$ & $\begin{array}{r}- \\
1.664\end{array}$ & 12 \\
\hline
\end{tabular}




\begin{tabular}{|c|c|c|c|c|c|c|c|c|}
\hline $\mathrm{e}^{\text {naiv }}$ & 11.3 & 12.2 & 14.3 & 7.5 & 14.6 & 0 & $\begin{array}{r}- \\
0.727\end{array}$ & 17.1 \\
\hline M14 & 13 & 15.2 & 13.3 & 10.5 & 16.2 & 0.18 & $1.044^{-}$ & 18.7 \\
\hline M6 & 14 & 9.9 & 10 & 22 & 17.6 & $\begin{array}{r}- \\
0.47 \\
\end{array}$ & $\begin{array}{r}- \\
1.537 \\
\end{array}$ & 8.1 \\
\hline M16 & 14.2 & 11.8 & 10 & 20.8 & 16.6 & $\begin{array}{r}- \\
0.29\end{array}$ & $\begin{array}{r}- \\
1.228\end{array}$ & 13.9 \\
\hline M1 & 15.8 & 20.6 & 10.4 & 16.4 & 16.8 & $\begin{array}{r}- \\
0.33\end{array}$ & $\begin{array}{r}- \\
1.301\end{array}$ & 12.8 \\
\hline M28 & 20 & 18.3 & 24.2 & 17.4 & 23.5 & $\begin{array}{r}- \\
1.51\end{array}$ & 3.343 & 17.4 \\
\hline
\end{tabular}

813

814 


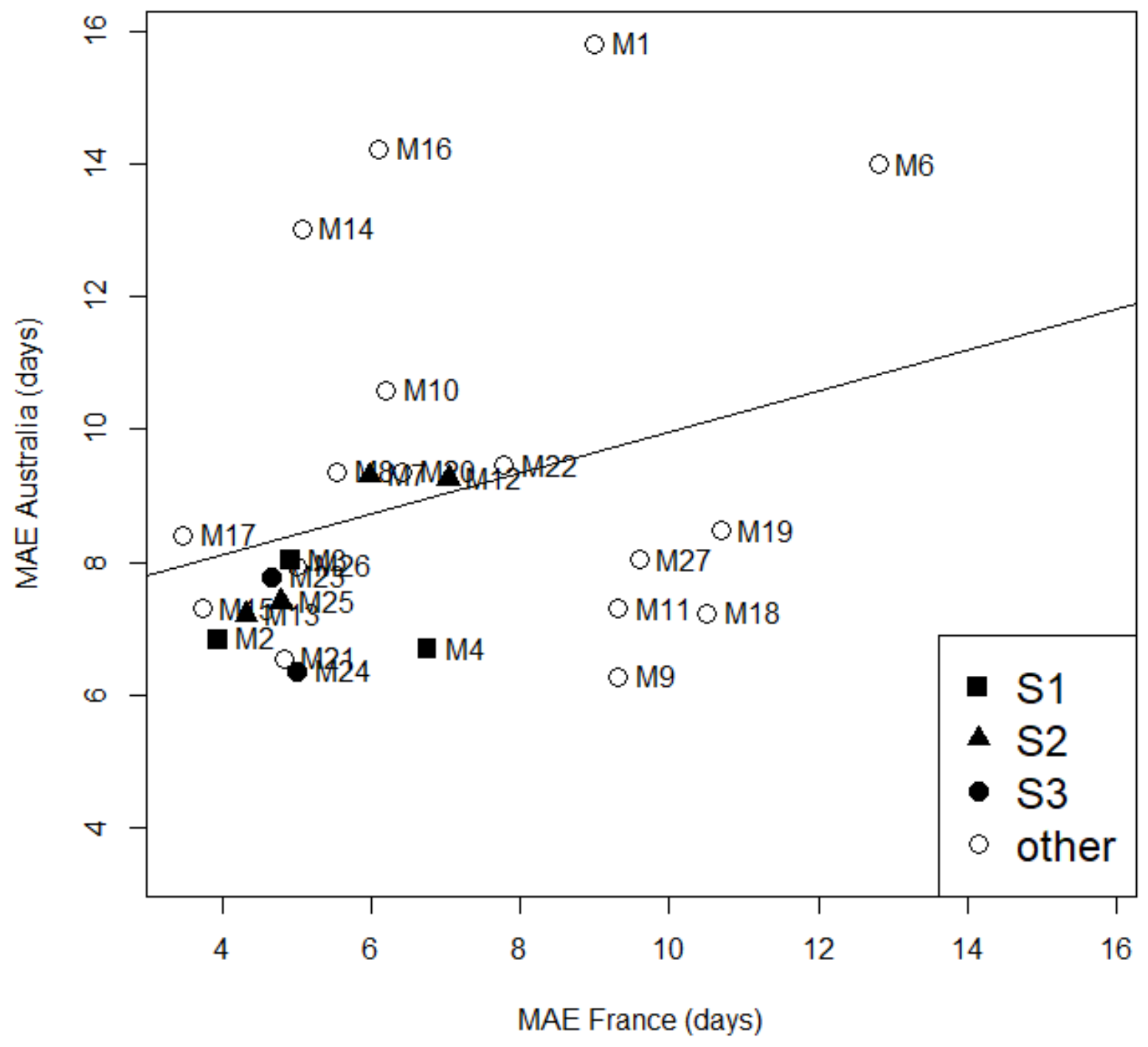
and MAE for the French environments, for modeling groups that participated in both studies. Values are averages over predicted development stages. Points are identified by modeling group. Modeling groups that shared the same structure (S1, S2 or S3) are identified by filled squares, triangles or circles, respectively. The regression line is $823 \mathbf{y}=\mathbf{8 . 2 3 + 0 . 2 4 x}$. 